Supporting Information for:

\title{
A rational approach to identify RNA targets of natural products enables identification of nocathiacin as an inhibitor of an oncogenic RNA
}

Fei Ye ${ }^{1, \dagger}$, Hafeez S. Haniff ${ }^{1, \dagger}$, Blessy M. Suresh ${ }^{1, \dagger}$, Dong Yang ${ }^{1,4}$, Peiyuan Zhang ${ }^{1}$, Gogce

Crynen ${ }^{2}$, Christiana N. Teijaro ${ }^{1}$, Wei Yan ${ }^{1}$, Daniel Abegg ${ }^{1}$, Alexander Adibekian ${ }^{1}$, Ben Shen $1,3,4, *$, and Matthew D. Disney ${ }^{1, *}$

${ }^{1}$ Department of Chemistry, The Scripps Research Institute, Jupiter, FL 33458, USA

${ }^{2}$ Bioinformatics core, The Scripps Research Institute, Jupiter, FL 33458, USA

${ }^{3}$ Department of Molecular Medicine, The Scripps Research Institute, Jupiter, FL 33458, USA

${ }^{4}$ Natural Products Discovery Center at Scripps Research, The Scripps Research Institute, Jupiter, FL 33458, USA

*Authors to whom correspondence should be addressed: Disney@scripps.edu;

shenb@scripps.edu 


\section{Table of Contents}

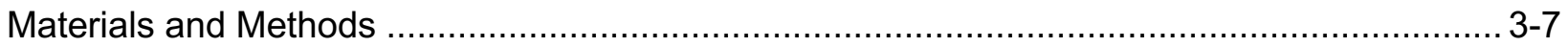

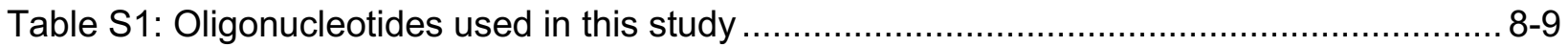

Table S2: The four media used to ferment strains from our in-house collection to construct the

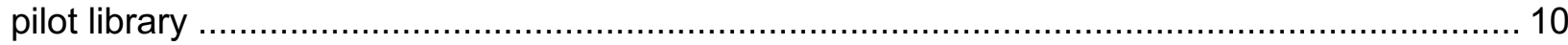

Table S3: Comparison of pre-miR-18a binders ......................................................... 11

Table S4: Secondary structures of RNAs containing 5'GAU/3'C_A RNA fold................... 12-13

Table S5: List of proteins upregulated and downregulated as identified via global proteomics analysis.

Figure S1: Structure of the 72 selected pure natural products

$15-18$

Figure S2: Physiochemical properties of the 72 natural products selected to study for their ability to bind RNA

Figure S3: Confirmed hits for $3 \times 3$ and $3 \times 2$ ILLs from screening the pilot library .................. 20

Figure S4: NOC-I detection in scale-up fermentation ............................................ 21

Figure S5: Absorb array identifies Nocathiacin-I (NOC-I) as an RNA binder ........................ 22

Figure S6: RNA targets of NOC-I identified via HiT-StARTS ............................................ 23

Figure S7: Fluorescence properties of NOC-I and binding affinities of RNA targets ............ 24-25

Figure S8: NOC-I binds pre-miR-18a's Dicer site avidly .............................................. 26

Figure S9: NOC-I inhibits processing of pre-miR-18a by Dicer in vitro ................................ 27

Figure S10: Predicted selectivity of NOC-I and a previously identified inhibitor of pre-milR-18a

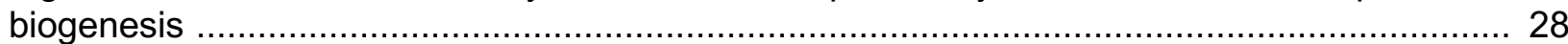

Figure S11: Effect of NOC-I on mature miRNA levels of miR-17/92 cluster members as measured by RT-qPCR

Figure S12: Forced expression of pre-miR-18a or pri-miR-17/92 reduces the activity NOC-I in DU145 prostate cancer cells, as assessed by measurement of mature miR-18a levels by RT-qPCR.

Figure S13: NOC-I effects on other miR targets predicted by Inforna ............................... 31

Figure S14: Multiple sequences alignment for ribosomal protein L11 .............................. 32

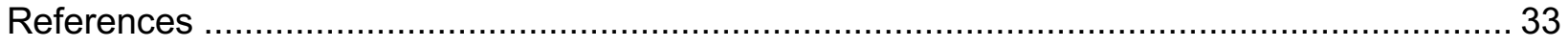




\section{MATERIALS \& METHODS}

General. RNA libraries used in this study were transcribed in vitro as previously described. ${ }^{1}$ All primers and oligonucleotides were used directly from the supplier. Autoradiography was completed by using a Typhoon FLA9500 variable mode imager (GE Healthcare).

All chemicals were obtained from commercial sources. NMR spectra were recorded on a Bruker AVANCE AV600 spectrometer (600 MHz, ${ }^{1} \mathrm{H}$ NMR). LC-MS was performed on an Agilent 1260 Infinity LC coupled to a 6230 TOF (HR-ESI) equipped with an Agilent Poroshell 120 EC-C18 column (50 $\mathrm{mm} \times 4.6 \mathrm{~mm}, 2.7 \mu \mathrm{m})$. During the isolation process, a Biotage Isolera, equipped with a C18 column (SNAP Cartridge KP-C18-HS, 60g), and an Agilent 1260 Infinity II with the detector 1260 MWD and C18 column (Agilent ZORBAX SB-C18, $5 \mu \mathrm{m}, 9.4 \times 250 \mathrm{~mm}$ ) were used for fractionation and purification, respectively.

\section{Construction of the actinobacteria strain collection and natural product library at TSRI.}

The strain collection in the Natural Products Discovery Center (NPDC) at Scripps Research contains a total of 125,127 strains, including both our in-house collection and the historic pharma collection that Pfizer contributed to Scripps Research in 2018 , of which 62,328 are classified as actinobacteria, 14,465 as other bacteria, and 48,334 as unidentified. These strains were isolated over the last eight decades, and the 62,328 actinobacteria, spanning 88 different genera, were isolated from 69 different countries with different climate and ecology factors that further increase NP structural diversity. ${ }^{2}$

To facilitate the NPs discovery from these actinobacteria, we have constructed a natural products library (NPL) of 46,031 crude extracts, 28,739 partially purified fractions, and 650 pure NPs. Of these, the 46,031 crude extracts were made from 14,635 actinobacterial strains that were 
selected to represent the overall diversity of the TSRI strain collection, and were cultured, on average, in three or four different media to maximize NP production (Table S2). The 28,739 partially purified fractions were made from crude extracts of large-scale fermentation of 2,366 strains with the richest NP profiles, which were fractionated by medium-pressure C18 chromatography. The 650 pure NPs were isolated from 143 selected strains under the optimized fermentation conditions. Estimated based on $\sim 30$ biosynthetic gene clusters (BGCs) per strain, the 14,635 Actinobacteria could encode biosynthesis of $\sim 440,000$ NPs. Even with realization of only $20 \%$ of this potential under the cultured conditions, the collection could still afford $\sim 88,000$ NPs, which, in reference to the $\sim 20,000$ NPs of actinobacterial origin known to date ${ }^{3}$ provide an unprecedented source of rich and unique NP chemotypes to target structured RNAs.

In the current study, we constructed a pilot library, consisting of 72 NPs, biased towards the chemotypes of small molecules that bind $3 \times 3$ and $3 \times 2$ ILLs (Figures S1 and S2) from the Inforna database, and 11,273 crude extracts and 5,082 partially purified fractions, made from our inhouse strain collection at NPDC, and demonstrated the feasibility of two-dimensional combinational screening (2DCS) of the pilot library to identify NPs targeting structured RNAs.

To generate partially purified fractions, crude extracts were purified by reverse phase chromatography using a Biotage ${ }^{\circledR}$ SNAP Cartridge KP-C18-HS (30 g). Partially purified fractions were eluted in a series of steps: (i) $100 \% \mathrm{H}_{2} \mathrm{O}(\mathrm{A}$; $30 \mathrm{~mL}$ ); (ii) $5 \% \mathrm{MeOH}$ (B) in $\mathrm{A}(100 \mathrm{~mL}$ ); (iii) a linear gradient of $5-30 \% \mathrm{~B}$ in $\mathrm{A}(50 \mathrm{~mL})$; (iv) a linear gradient of $30 \%-100 \% \mathrm{~B}$ in $\mathrm{A}(312 \mathrm{~mL})$; and (v) $100 \%$ of $B(125 \mathrm{~mL})$, each with a flow rate of $20 \mathrm{~mL} / \mathrm{min}$ to afford 20 fractions. The fractions were lyophilized to dryness using Thermo vacuum concentrator overnight. The resulting residues were dissolved in $1 \mathrm{~mL}$ DMSO. The final concentration of the fractions was $4,000 \times$ as compared to the crude fraction.

Pure NPs were selected based on the physiochemical property calculation and compared with the RNA binders from Inforna database. 
Calculation of molecular properties. The molecular properties of chemical compounds in the Inforna database and NPs library were calculated using ChemAxon's Instant JChem software. ${ }^{4}$

Culture and fermentation for producer of nocathiacin I (ATCC 202099). Culture and fermentation for nocathiacin I (NOC-I) producer, ATCC 202099, were conducted as previously described. ${ }^{5}$ Briefly, the strain, from a glycerol stock $\left(-80^{\circ} \mathrm{C}\right)$, was revived on ISP4 culture medium at $28^{\circ} \mathrm{C}$. The spores were inoculated into seed medium $(1 \%(\mathrm{w} / \mathrm{w})$ glycerol, $2 \%(\mathrm{w} / \mathrm{v})$ galactose, $2 \%(\mathrm{w} / \mathrm{v})$ dextrin, $1 \%(\mathrm{w} / \mathrm{v})$ Baco soytone, $0.2 \%(\mathrm{v} / \mathrm{v})$ corn steep liquor, $0.2 \%(\mathrm{w} / \mathrm{v})\left(\mathrm{NH}_{4}\right)_{2} \mathrm{SO}_{4}$, $0.2 \%(\mathrm{w} / \mathrm{v}) \mathrm{CaCO}_{3}, \mathrm{pH} 7.0$ ) and cultured for 2 days. NOC-I production medium (same as the seed culture medium) was inoculated with $5 \%(\mathrm{v} / \mathrm{v})$ seed culture and incubated at $28{ }^{\circ} \mathrm{C}$ and $250 \mathrm{rpm}$ for 4 days in $400 \mathrm{~mL}$ of medium in $2 \mathrm{~L}$ flasks.

Isolation and purification of NOC-I. Six liters of production culture was harvested after 4 days of fermentation. Supernatant and mycelia were well separated after centrifugation (4,000 rpm for 30 min at $\left.4{ }^{\circ} \mathrm{C}\right)$. The production of NOC-I in both methanol $(\mathrm{MeOH})$ extract of mycelia and ethyl acetate (EtOAc) extract from supernatant were detected by LC-MS analysis (Figure S3). Both organic extracts were combined and evaporated to give a residue (4.2 g), which was subjected to flash chromatography using a Biotage Isolera purification system equipped with a C18 column (60 g of $\mathrm{C} 18$ resin loaded), with a gradient elution from $0 \%$ to $100 \% \mathrm{MeOH}$ in $\mathrm{H}_{2} \mathrm{O}$ over 35 min at a flow rate of $25 \mathrm{~mL} / \mathrm{min}$ ), yielding five fractions. Fraction 3 was further separated by Sephadex LH-20 (eluted with $\mathrm{MeOH}$ ) and NOC-I was concentrated in subfraction 3b. Further purification of subfraction $3 b$ was conducted by RP-HPLC with a gradient elution from 10:90:0.1\% to 100:0:0.1\% 
of acetonitrile $(\mathrm{MeCN}) / \mathrm{H}_{2} \mathrm{O} / \mathrm{HCl}$ over $20 \mathrm{~min}$ at a flow rate of $3.0 \mathrm{~mL} / \mathrm{min}$, affording $\mathrm{NOC}-\mathrm{I}$ (38.0 $\left.\mathrm{mg}, \mathrm{R}_{\mathrm{t}}=13.3 \mathrm{~min}\right)$.

Preparation of microarrays containing NPs. Small molecule microarrays were prepared as previously described, i.e., by AbsorbArray. ${ }^{6}$ Briefly, $13 \mathrm{~mL}$ of $1 \%(\mathrm{w} / \mathrm{v})$ molten agarose solution was applied to a $12.7 \times 8.4 \mathrm{~cm}$ glass slide, and the agarose was allowed to dry to a thin gel layer at room temperature for $1.5 \mathrm{~h}$. After drying, $300 \mathrm{~nL}$ of $10 \mathrm{mM}$ stock of NPs in a 384-well plate (Greiner, 781209) was pinned onto the surface using a Biomek NXP Laboratory Automation Workstation that was equipped with a 384-pin head. The compound-spotted slides were allowed to dry completely overnight.

Transfection of pri-miR-17-92 or pre-miR-18a. To study the effect of overexpressing the miR17-92 cluster or pre-miR-18a on the activity of NOC-I and to confirm the dependence of activity on these miRNAs, we forced DU-145 to express the miR-17-92 cluster or pre-miR-18a. DU-145 cells were transfected with $5 \mu \mathrm{g}$ of a plasmid encoding the miR-17/92 cluster $^{7}$ or encoding premiR-18a (custom synthesized by GenScript) using Lipofectamine 3000 per the manufacturer's protocol for $6 \mathrm{~h}$. After transfection, the cells were washed twice with DPBS and then allowed to recover in growth medium for $8 \mathrm{~h}$ before re-plating into 12-well or 96-well plates. RT-qPCR and Caspase 3/7 Glo studies were then carried out as described above. [RT-qPCR analysis of untreated cells showed that forced expression increased pre-miR-18a levels by $\sim 3$-fold and primiR-17/92 levels by $\sim 2$-fold, as compared to endogenous levels.]

Global proteomics profiling using LC-MS/MS. Cells were resolubilized in 1× PBS, lysed via sonication, and protein concentration was determined using a Bradford assay (Bio-Rad). 
Samples $(30 \mu \mathrm{g})$ were denatured with $6 \mathrm{M}$ urea in $50 \mathrm{mM} \mathrm{NH}_{4} \mathrm{HCO}_{3}, \mathrm{pH}$ 8, reduced with $10 \mathrm{mM}$ TCEP for $30 \mathrm{~min}$, and alkylated with $25 \mathrm{mM}$ iodoacetamide for $30 \mathrm{~min}$ in the dark. Samples were diluted to $2 \mathrm{M}$ Urea with $50 \mathrm{mM} \mathrm{NH}_{4} \mathrm{HCO}_{3}, \mathrm{pH} 8$ and digested with trypsin $(1.5 \mu \mathrm{L}$ of $0.5 \mu \mathrm{g} / \mu \mathrm{L})$ in the presence of $1 \mathrm{mM} \mathrm{CaCl}_{2}$ for $12 \mathrm{~h}$ at $37^{\circ} \mathrm{C}$. Samples were acidified by addition of acetic acid 5\% (v/v), desalted over a self-packed C18 spin column, and dried. Samples were analyzed by LC-MS/MS and the MS data was processed with MaxQuant (see below).

LC-MS/MS and MaxQuant analysis. Peptides were resuspended in water with $0.1 \%(\mathrm{v} / \mathrm{v})$ formic acid (FA) and analyzed using EASY-nLC 1200 nano-UHPLC coupled to a Q Exactive HF-X Quadrupole-Orbitrap mass spectrometer (Thermo Scientific). LC-MS/MS analysis was carried out using a column with the following specifications: $50 \mathrm{~cm}$ long, $75 \mu \mathrm{m}$ i.d. microcapillary capped by a $5 \mu \mathrm{m}$ tip and packed with ReproSil-Pur 120 C18-AQ $2.4 \mu \mathrm{m}$ beads (Dr. Maisch $\mathrm{GmbH}$ ). Liquid chromatography was performed using the following solvents: $0.1 \%$ (v/v) FA in $\mathrm{H}_{2} \mathrm{O}$ (Buffer A) and $0.1 \%(v / v)$ FA in $90 \% \mathrm{MeCN}: 10 \% \mathrm{H}_{2} \mathrm{O}$ (Buffer B). A linear gradient (5-35\% Buffer B) with a flow rate of $300 \mathrm{~nL} / \mathrm{min}$ was applied over $240 \mathrm{~min}$ at $65^{\circ} \mathrm{C}$. All data were acquired in data dependent mode (top-20, NCE 28, $R=7,500$ ) after full MS scan ( $R=60,000, \mathrm{~m} / \mathrm{z} 400-1,300)$. The collection settings were set-up for dynamic exclusion at $10 \mathrm{~s}$, peptide matching to prefer, and isotope exclusion was set to enabled. MaxQuant ${ }^{1}(\mathrm{~V} 1.6 .1 .0)$ was used to analyze the data, and the results were searched against the human proteome (Uniprot) and a common list of contaminants (included in MaxQuant). Peptide search tolerances were set to $20 \mathrm{ppm}$ at first pass, with $10 \mathrm{ppm}$ being used for the main peptide search with a fragment mass tolerance of $0.02 \mathrm{Da}$. The false discovery rate for peptides and proteins was set to $1 \%$ with a minimum peptide length of six amino acids, peptide re-quantification, label-free quantification (MaxLFQ) and 'match between runs' were also enabled. Methionine oxidation was searched as a variable modification, and carbamidomethylation of cysteines was searched as a fixed modification. 


\begin{tabular}{|c|c|c|c|}
\hline Oligonucleotide & Sequence $5^{\prime} \rightarrow 3^{\prime}$ & Experiment & Supplier \\
\hline hsa-miR-17 & CAAAGTGCTTACAGTGCAGGTAC & RT-qPCR & Europhins \\
\hline has-miR-18a & TAAGGTGCATCTAGTGCAGATAG & RT-qPCR & Europhins \\
\hline has-miR-19a & TGTGCAAATCTATGCAAAACTGA & RT-qPCR & Europhins \\
\hline has-miR-20a & TAAAGTGCTTATAGTGCAGGTAG & RT-qPCR & Europhins \\
\hline has-miR-19b & TGTGCAAATCCATGCAAAACTGA & RT-qPCR & Europhins \\
\hline has-miR-92a-1 & TATTGCACTTGTCCCGGCCTGT & RT-qPCR & Europhins \\
\hline RNU6 & ACACGCAAATTCGTGAAGCGTTC & \begin{tabular}{|l|} 
RT-qPCR \\
\end{tabular} & IDT \\
\hline Universal Reverse & GAATCGAGCACCAGTTACGC & RT-qPCR & IDT \\
\hline $\begin{array}{l}\text { Pri-miR-17/92 5' } \\
\text { Fwd }\end{array}$ & GGAATTAATTGCTGTTAGGAGGTTGGA & RT-qPCR & IDT \\
\hline $\begin{array}{l}\text { Pri-miR-17/92 5' } \\
\text { Rev }\end{array}$ & AGGTCCACGTGTATGACTGG & RT-qPCR & IDT \\
\hline STK4 Fwd & GATGGGCACTGTCCGAGTAG & RT-qPCR & IDT \\
\hline STK4 Rev & GCAACGTGTCATCGTGCTC & RT-qPCR & IDT \\
\hline 18S Fwd & GTAACCCGTTGAACCCCATT & RT-qPCR & IDT \\
\hline 18S Rev & CCATCCAATCGGTAGTAGCG & RT-qPCR & IDT \\
\hline $\begin{array}{l}\text { Pre-miR-18a } \mathrm{T7} \\
\text { Fwd }\end{array}$ & $\begin{array}{l}\text { GGCCGCATGGTAATACGACTCACTATAGGT } \\
\text { AAGGTGCAT CTAGTGCAG }\end{array}$ & Dicer Inhibition & IDT \\
\hline Pre-miR-18a Rev & CCAGAAGGAGCACTTAGG & Dicer Inhibition & IDT \\
\hline $\begin{array}{l}\text { Pre-miR-18a } \\
\text { Template (wild- } \\
\text { type) }\end{array}$ & $\begin{array}{l}\text { TAAGGTGCATCTAGTGCAGATAGTGAAGTA } \\
\text { GATTAG } \\
\text { CATCTACTGCCCTAAGTGCTCCTTCTGG }\end{array}$ & Dicer Inhibition & IDT \\
\hline $\begin{array}{l}\text { Pre-miR-18a-U37 } \\
\text { Template (mutant) }\end{array}$ & $\begin{array}{l}\text { TAAGGTGCATCTAGTGCAGATAGATGAAGT } \\
\text { AGATTAG } \\
\text { CATCTACTGCCCTAAGTGCTCСTTCTGG }\end{array}$ & Dicer Inhibition & IDT \\
\hline Pre-miR-18a Fwd. & TAAGGTGCATCTAGTGCAGATAG & RT-qPCR & IDT \\
\hline Pre-miR-18a Rev & GAAGGAGCACTTAGGGCAGT & RT-qPCR & IDT \\
\hline Gapmer 1-14 & $\begin{array}{l}\text { 1-14: } m C^{*} m A^{*} m C^{*} T^{*} A^{*} G^{*} A^{*} T^{*} G^{*} C^{*} A^{*} m C^{*} \\
m C^{*} T\end{array}$ & ASO-Bind-Map & IDT \\
\hline Gapmer 15-28 & $\begin{array}{l}\text { 15-28: } T^{*} m A^{*} m C^{*} \quad T^{*} T^{*} C^{*} \quad A^{*} C^{*} T^{*} \quad A^{*} T^{*} m C^{*} \\
T^{*} m G\end{array}$ & ASO-Bind-Map & IDT \\
\hline Gapmer 26-39 & $\begin{array}{l}\text { 26-39: } m A^{*} m G^{*} m A^{*} T^{*} G^{*} C^{*} T^{*} A^{*} A^{*} T^{*} C^{*} T^{*} \\
m A^{*} m C\end{array}$ & ASO-Bind-Map & IDT \\
\hline $\begin{array}{l}\text { Scrambled } \\
\text { Gapmer }\end{array}$ & $m G^{*} m A^{*} m G^{*} T^{*} T^{*} G^{*} T^{*} T^{*} C^{*} C^{*} T^{*} m C^{*} m G^{*} T$ & ASO-Bind-Map & IDT \\
\hline $\begin{array}{l}\text { 5'CUC/3'G_G } \\
\text { motif }\end{array}$ & $\begin{array}{l}\text { GGGAGAGGGTTTAATCTCTACGAAAGTAG } \\
\text { GATTGGATCCGCAAGG }\end{array}$ & Binding Assay & IDT \\
\hline 5'GAU/3'C_A motif & $\begin{array}{l}\text { GGGAGAGGGTTTAATGATTACGAAAGTAAC } \\
\text { ATTGGATCCGCAAGG }\end{array}$ & Binding Assay & IDT \\
\hline $\begin{array}{l}\text { 5'GGA/3'C_C }_{\text {motif }}\end{array}$ & $\begin{array}{l}\text { GGGAGAGGGTTTAATGGATACGAAAGTAC } \\
\text { CATTGGATCCGCAAGG }\end{array}$ & Binding Assay & IDT \\
\hline $\begin{array}{l}\text { 5'UUA/3'G_G } \\
\text { motif }\end{array}$ & $\begin{array}{l}\text { GGGAGAGGGTTTAATTTATACGAAAGTAGG } \\
\text { ATTGGATCCGCAAGG }\end{array}$ & Binding Assay & IDT \\
\hline $\begin{array}{l}5^{\prime} G C C / 3^{\prime} C A G \\
\text { motif }\end{array}$ & $\begin{array}{l}\text { GGGAGAGGGTTTAATGCCTACGAAAGTAG } \\
\text { ACATTGGATCCGCAAGG }\end{array}$ & Binding Assay & IDT \\
\hline 5'AAA/3'UUA motif & $\begin{array}{l}\text { GGGAGAGGGTTTAATAAATACGAAAGTAAT } \\
\text { TATTGGATCCGCAAGG }\end{array}$ & Binding Assay & IDT \\
\hline 5'UUC/3'G_A motif & $\begin{array}{l}\text { GGGAGAGGGTTTAATTTCTACGAAAGTAAG } \\
\text { ATTGGATCCGCAAGG }\end{array}$ & Binding Assay & IDT \\
\hline $\begin{array}{l}\text { 5'CCA/3'G_G }_{\text {motif }} \\
\text { mats }\end{array}$ & $\begin{array}{l}\text { GGGAGAGGGTTTAATCCATACGAAAGTAG } \\
\text { GATTGGATCCGCAAGG }\end{array}$ & Binding Assay & IDT \\
\hline
\end{tabular}




\begin{tabular}{|l|l|l|l|}
\hline $5^{\prime} U U C / 3^{\prime A}$ _C motif & $\begin{array}{l}\text { GGGAGAGGGTTTAATTTCTACGAAAGTACA } \\
\text { ATTGGATCCGCAAGG }\end{array}$ & Binding Assay & IDT \\
\hline 5'AAA/3'AAU motif & $\begin{array}{l}\text { GGGAGAGGGTTTAATAATACGAAAGTATA } \\
\text { AATTGGATCCGCAAGG }\end{array}$ & Binding Assay & IDT \\
\hline 5'AAA/3'CUU motif & $\begin{array}{l}\text { GGGAGAGGGTTTAATAAATACGAAAGTATT } \\
\text { CATTGGATCCGCAAGG }\end{array}$ & Binding Assay & IDT \\
\hline 5'UUA/3'U_U motif & $\begin{array}{l}\text { GGGAGAGGGTTTAATTATACGAAAGTATT } \\
\text { ATTGGATCCGCAAGG }\end{array}$ & Binding Assay & IDT \\
\hline 5'CAU/3'G_U motif & $\begin{array}{l}\text { GGGAGAGGGTTTAATCATTACGAAAGTATG } \\
\text { ATTGGATCCGCAAGG }\end{array}$ & Binding Assay & IDT \\
\hline 5'AGA/3'U_U motif & $\begin{array}{l}\text { GGGAGAGGGTTTAATAGATACGAAAGTATT } \\
\text { ATTGGATCCGCAAGG }\end{array}$ & Binding Assay & IDT \\
\hline 5'CUC/3'U_C motif & $\begin{array}{l}\text { GGGAGAGGGTTTAATCTCTACGAAAGTACT } \\
\text { ATTGGATCCGCAAGG }\end{array}$ & Binding Assay & IDT \\
\hline $\begin{array}{l}\text { 5'UCC/3'ACG } \\
\text { motif }\end{array}$ & $\begin{array}{l}\text { GGGAGAGGGTTTAATTCCTACGAAAGTAGC } \\
\text { AATTGGATCCGCAAGG }\end{array}$ & Binding Assay & IDT \\
\hline 5'AGA/3'AAC motif & $\begin{array}{l}\text { GGGAGAGGGTTTAATAGATACGAAAGTACA } \\
\text { AATTGGATCCGCAAGG }\end{array}$ & Binding Assay & IDT \\
\hline $\begin{array}{l}\text { 5'UUU/3'UAC } \\
\text { motif }\end{array}$ & $\begin{array}{l}\text { GGGAGAGGGTTTAATTTTACGAAAGTACA } \\
\text { TATTGGATCCGCAAGG }\end{array}$ & Binding Assay & IDT \\
\hline $\begin{array}{l}\text { 5'UAC/3'AUG } \\
\text { motif }\end{array}$ & $\begin{array}{l}\text { GGGAGAGGGTTTAATTACTACGAAAGTAGT } \\
\text { AATTGGATCCGCAAGG }\end{array}$ & Binding Assay & IDT \\
\hline
\end{tabular}

Many oligonucleotides are originally referenced from Liu et al. ${ }^{8} \mathrm{mN}^{*}=2$ '-O-methyl modified base; $\mathrm{N}^{*}=$ phosphorothioate modified base, where $\mathrm{N}=\mathrm{A}, \mathrm{T}, \mathrm{G}$ or $\mathrm{C}$. 


\begin{tabular}{|l|l|}
\hline \multicolumn{2}{|l|}{ Table S2. The four media used to ferment strains from our in-house collection to contract the pilot library } \\
\hline Medium & Components \\
\hline 1 & Soluble starch: $20 \mathrm{~g} / \mathrm{L}$ \\
& Glucose: $10 \mathrm{~g} / \mathrm{L}$ \\
& Peptone: $5 \mathrm{~g} / \mathrm{L}$ \\
& Yeast extract: $5 \mathrm{~g} / \mathrm{L}$ \\
& NaCl: $4 \mathrm{~g} / \mathrm{L}$ \\
& $\mathrm{K}_{2} \mathrm{HPO}_{4}: 0.5 \mathrm{~g} / \mathrm{L}$ \\
& MgSO$_{4} \cdot 7 \mathrm{H}_{2} \mathrm{O}: 0.5 \mathrm{~g} / \mathrm{L}$ \\
& CaCO $_{3}: 2 \mathrm{~g} / \mathrm{L}, \mathrm{pH} 7$ \\
\hline 2 & Sucrose: $100 \mathrm{~g} / \mathrm{L}$ \\
& Glucose: $10 \mathrm{~g} / \mathrm{L}$ \\
& Casamino acids: $0.1 \mathrm{~g} / \mathrm{L}$ \\
& Yeast extract: $5 \mathrm{~g} / \mathrm{L}$ \\
& MOPS: $21 \mathrm{~g} / \mathrm{L}$ \\
& Trace elements: $1 \mathrm{~mL}$ \\
& K2SO $: 0.25 \mathrm{~g} / \mathrm{L}$ \\
& MgCl$: 6 \mathrm{H}_{2} \mathrm{O}: 10 \mathrm{~g} / \mathrm{L}, \mathrm{pH} 7$ \\
\hline 3 & Dextrin: $40 \mathrm{~g} / \mathrm{L}$ \\
& Tomato paste: $7.5 \mathrm{~g} / \mathrm{L}$ \\
& NA Amine A: $2.5 \mathrm{~g} / \mathrm{L}$ \\
& Primary yeast: $5 \mathrm{~g} / \mathrm{L}, \mathrm{pH} 7$ \\
\hline 4 & Glycerol: $50 \mathrm{~g} / \mathrm{L}$ \\
& Corn meal: $25 \mathrm{~g} / \mathrm{L}$ \\
& Ardamine: $5 \mathrm{~g} / \mathrm{L}, \mathrm{pH} 7$ \\
\hline
\end{tabular}




\begin{tabular}{|c|c|c|}
\hline \multicolumn{3}{|c|}{ Table S3. Comparison of miR-18a binders NOC-I and the substituted benzimidazole. } \\
\hline Compound Structure & Effective Binding Partners & $\mathbf{K}_{d}(\mu \mathrm{M})$ \\
\hline NOC-I & 5'GAU/3'C_A (miR-18a) & $8 \pm 2$ \\
\hline \multirow{3}{*}{ Substituted benzimidazole } & 5'G_U/3'CUA (miR-17, -18a, and -20a) & $30 \pm 2$ \\
\hline & 5'GGU/3'C_A (miR-17 and -20a) & $40 \pm 6$ \\
\hline & 5'GAU/3'C_A (miR-18a) & $32 \pm 2$ \\
\hline
\end{tabular}




\begin{tabular}{|c|c|}
\hline $\begin{array}{c}\text { miRNA } \\
\text { (Abundance } \\
\text { relative to 18a)* }\end{array}$ & Secondary Structure \\
\hline $\begin{array}{l}\text { hsa-let-7g } \\
1.6\end{array}$ & 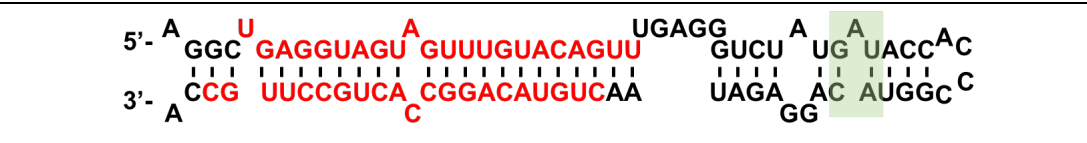 \\
\hline $\begin{array}{l}\text { hsa-miR-101-1 } \\
0.02\end{array}$ & 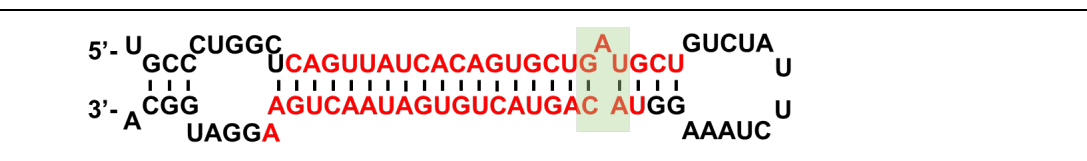 \\
\hline $\begin{array}{l}\text { hsa-miR-155 } \\
0.54\end{array}$ & 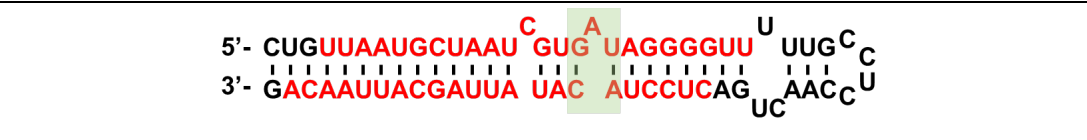 \\
\hline $\begin{array}{c}\text { hsa-miR-196a-2 } \\
0.64\end{array}$ & 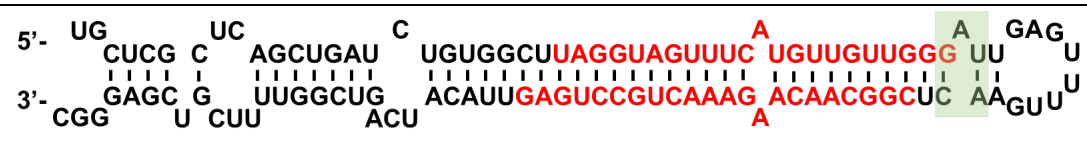 \\
\hline $\begin{array}{l}\text { hsa-miR-363 } \\
0.02\end{array}$ & 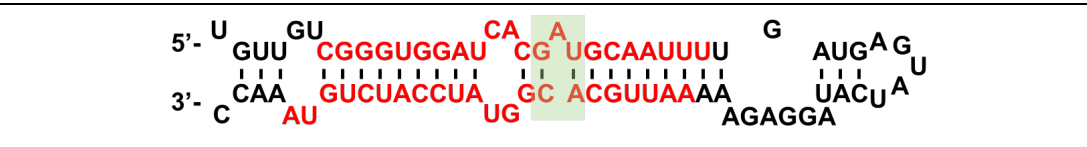 \\
\hline $\begin{array}{l}\text { hsa-miR-1226 } \\
0.04\end{array}$ & 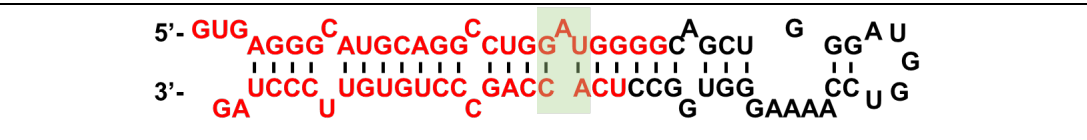 \\
\hline $\begin{array}{l}\text { hsa-miR-3168 } \\
0.05\end{array}$ & 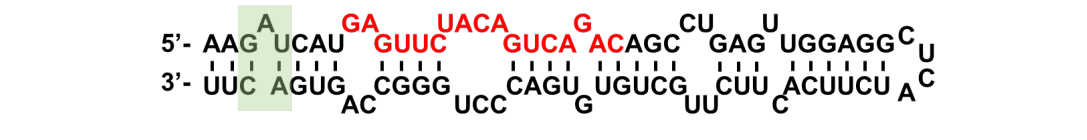 \\
\hline $\begin{array}{l}\text { hsa-miR-3945 } \\
0.02\end{array}$ & 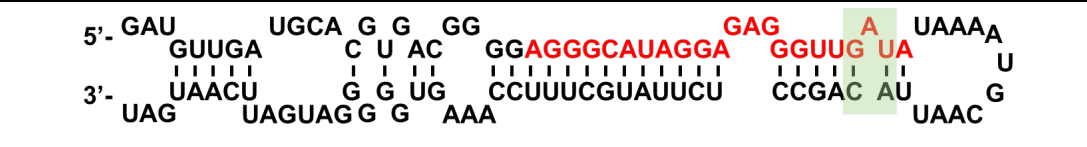 \\
\hline $\begin{array}{l}\text { hsa-miR-4273 } \\
0.11\end{array}$ & 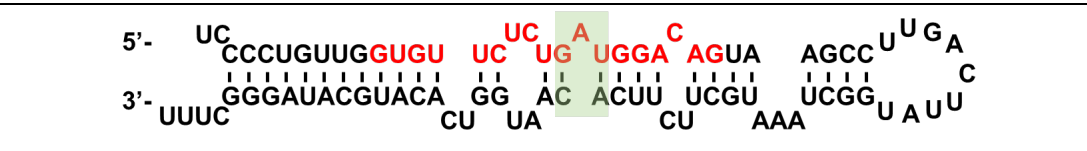 \\
\hline $\begin{array}{l}\text { hsa-miR-4435-1 } \\
0.05\end{array}$ & 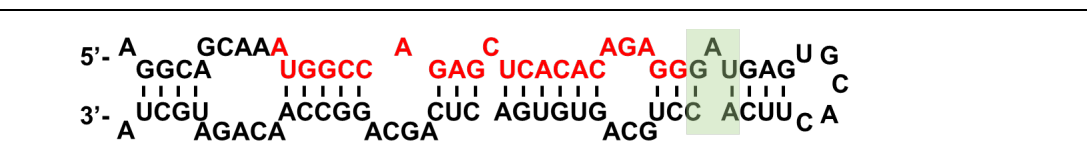 \\
\hline
\end{tabular}




\begin{tabular}{|c|c|}
\hline $\begin{array}{c}\text { hsa-miR-4435-2 } \\
0.05\end{array}$ & 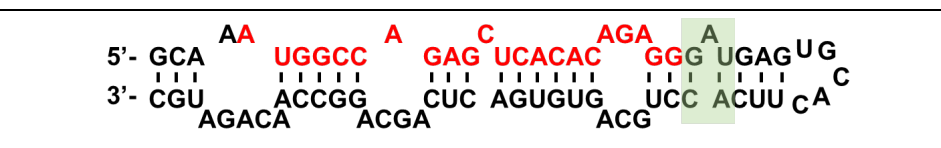 \\
\hline $\begin{array}{c}\text { hsa-miR-4454 } \\
2.1\end{array}$ & 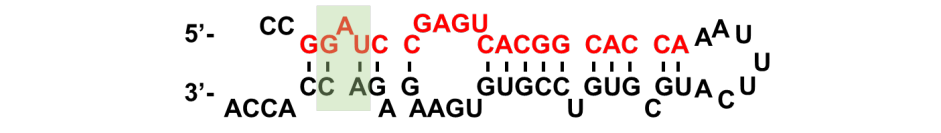 \\
\hline $\begin{array}{l}\text { hsa-miR-4640 } \\
0.5\end{array}$ & 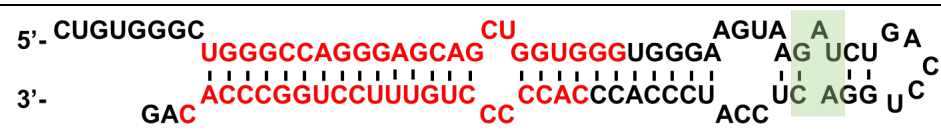 \\
\hline $\begin{array}{c}\text { hsa-miR-4700 } \\
0.14\end{array}$ & 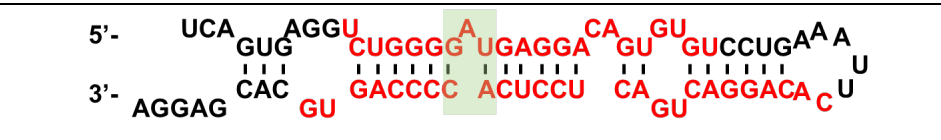 \\
\hline
\end{tabular}

${ }^{*}$ Reported abundances were taken from published studies. ${ }^{8}$ 


\begin{tabular}{|c|c|c|c|}
\hline Upregulated proteins & $\begin{array}{l}\log _{2} \text { fold } \\
\text { change }\end{array}$ & Downregulated proteins & $\begin{array}{l}\log _{2} \text { fold } \\
\text { change }\end{array}$ \\
\hline DAG1 (Dystroglycan) & 3.7 & $\begin{array}{l}\text { LYN (Tyrosine-protein kinase } \\
\text { Lyn) }\end{array}$ & -2.5 \\
\hline ATM (Serine-protein kinase ATM) & 3.6 & $\begin{array}{l}\text { CCDC12 (Coiled-coil domain- } \\
\text { containing protein 12) }\end{array}$ & -1.9 \\
\hline $\begin{array}{l}\text { DHX57 (Putative ATP-dependent RNA } \\
\text { helicase DHX57) }\end{array}$ & 2.9 & $\begin{array}{l}\text { COX7A2 (Cytochrome c } \\
\text { oxidase subunit 7A2, } \\
\text { mitochondrial) }\end{array}$ & -1.8 \\
\hline $\begin{array}{l}\text { PSMB10 (Proteasome subunit beta type- } \\
\text { 10) }\end{array}$ & 2.8 & $\begin{array}{l}\text { ARMC6 (Armadillo repeat- } \\
\text { containing protein } 6 \text { ) }\end{array}$ & -1.7 \\
\hline $\begin{array}{l}\text { CKMT1 (Creatine kinase U-type, } \\
\text { mitochondrial) }\end{array}$ & 2.5 & $\begin{array}{l}\text { MRPS26 (28S ribosomal } \\
\text { protein S26, mitochondrial) }\end{array}$ & -1.5 \\
\hline $\begin{array}{l}\text { TTI1 (TELO2-interacting protein } 1 \\
\text { homolog) }\end{array}$ & 2.5 & & \\
\hline RFK (Riboflavin kinase) & 2.4 & & \\
\hline $\begin{array}{l}\text { ERGIC2 (Endoplasmic reticulum-Golgi } \\
\text { intermediate compartment protein 2) }\end{array}$ & 2.4 & & \\
\hline $\begin{array}{l}\text { DHX37 (Probable ATP-dependent RNA } \\
\text { helicase DHX37) }\end{array}$ & 2.3 & & \\
\hline HS1BP3 (HCLS1-binding protein 3) & 2.3 & & \\
\hline HTATSF1 (HIV Tat-specific factor 1) & 2.2 & & \\
\hline $\begin{array}{l}\text { MARK1 (Serine/threonine-protein kinase } \\
\text { MARK1) }\end{array}$ & 1.9 & & \\
\hline FBXO2 (F-box only protein 2 ) & 1.9 & & \\
\hline $\begin{array}{l}\text { NSMCE1 (Non-structural maintenance of } \\
\text { chromosomes element } 1 \text { homolog) }\end{array}$ & 1.7 & & \\
\hline YARS2 (Tyrosine--tRNA ligase) & 1.6 & & \\
\hline NRBP1 (Nuclear receptor-binding protein) & 1.5 & & \\
\hline $\begin{array}{l}\text { DNAAF5 (Dynein assembly factor } 5 \text {, } \\
\text { axonemal) }\end{array}$ & 1.4 & & \\
\hline $\begin{array}{l}\text { UBXN7 (UBX domain-containing protein } \\
\text { 7) }\end{array}$ & 1.1 & & \\
\hline CDC73 (Parafibromin) & 1.0 & & \\
\hline APLP2 (Amyloid-like protein 2) & 0.9 & & \\
\hline SPINT2 (Kunitz-type protease inhibitor 2) & 0.8 & & \\
\hline
\end{tabular}




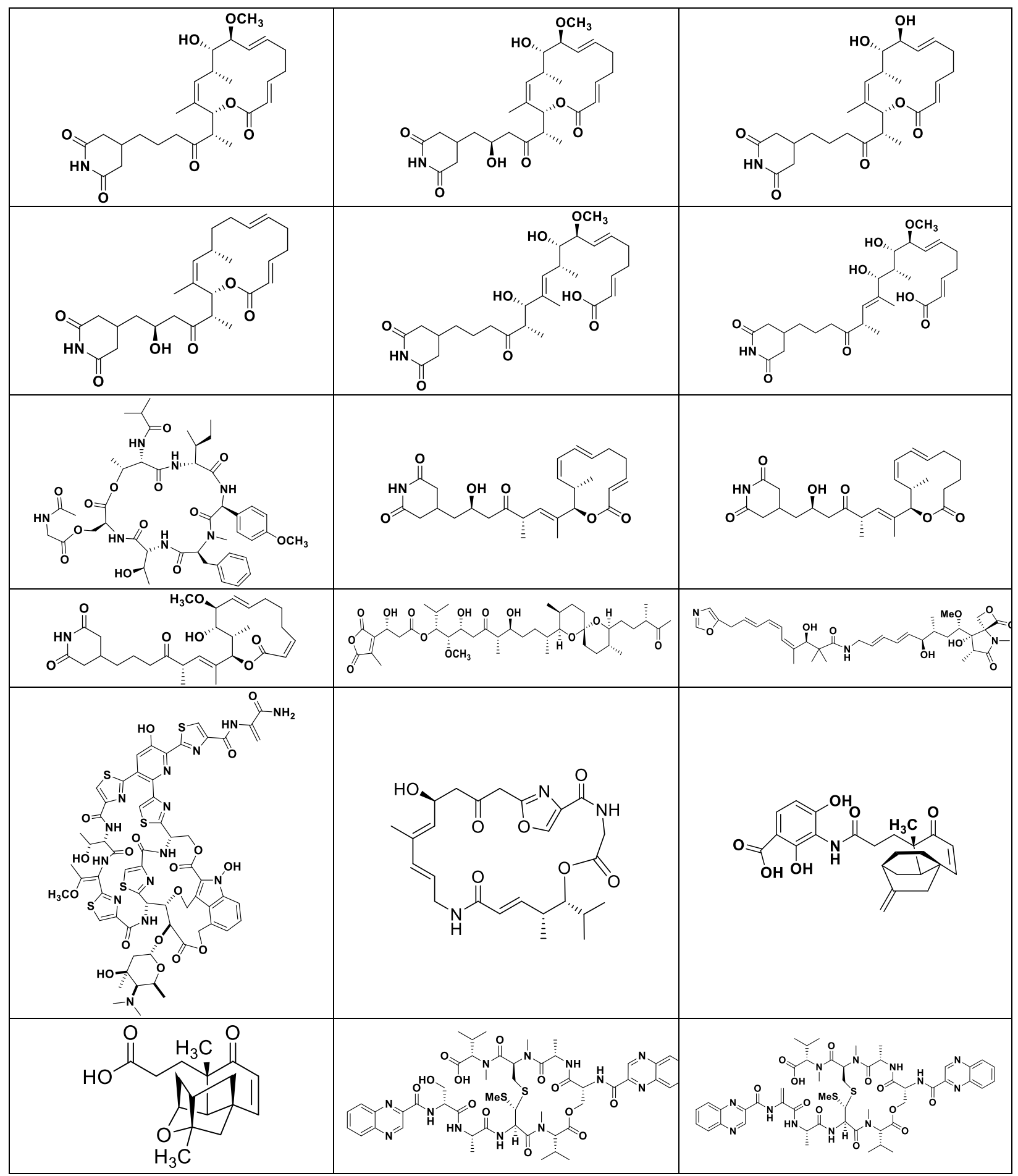




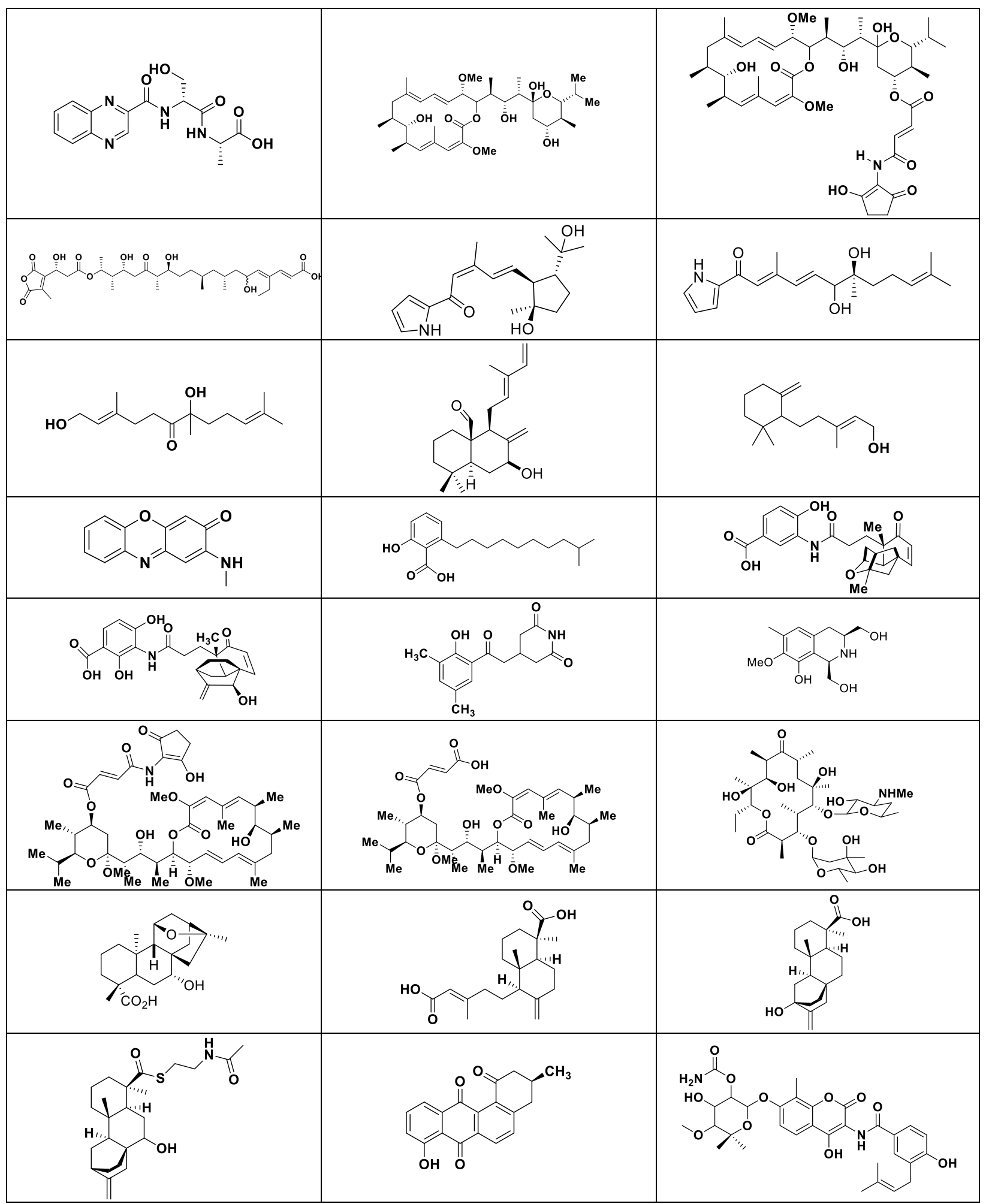




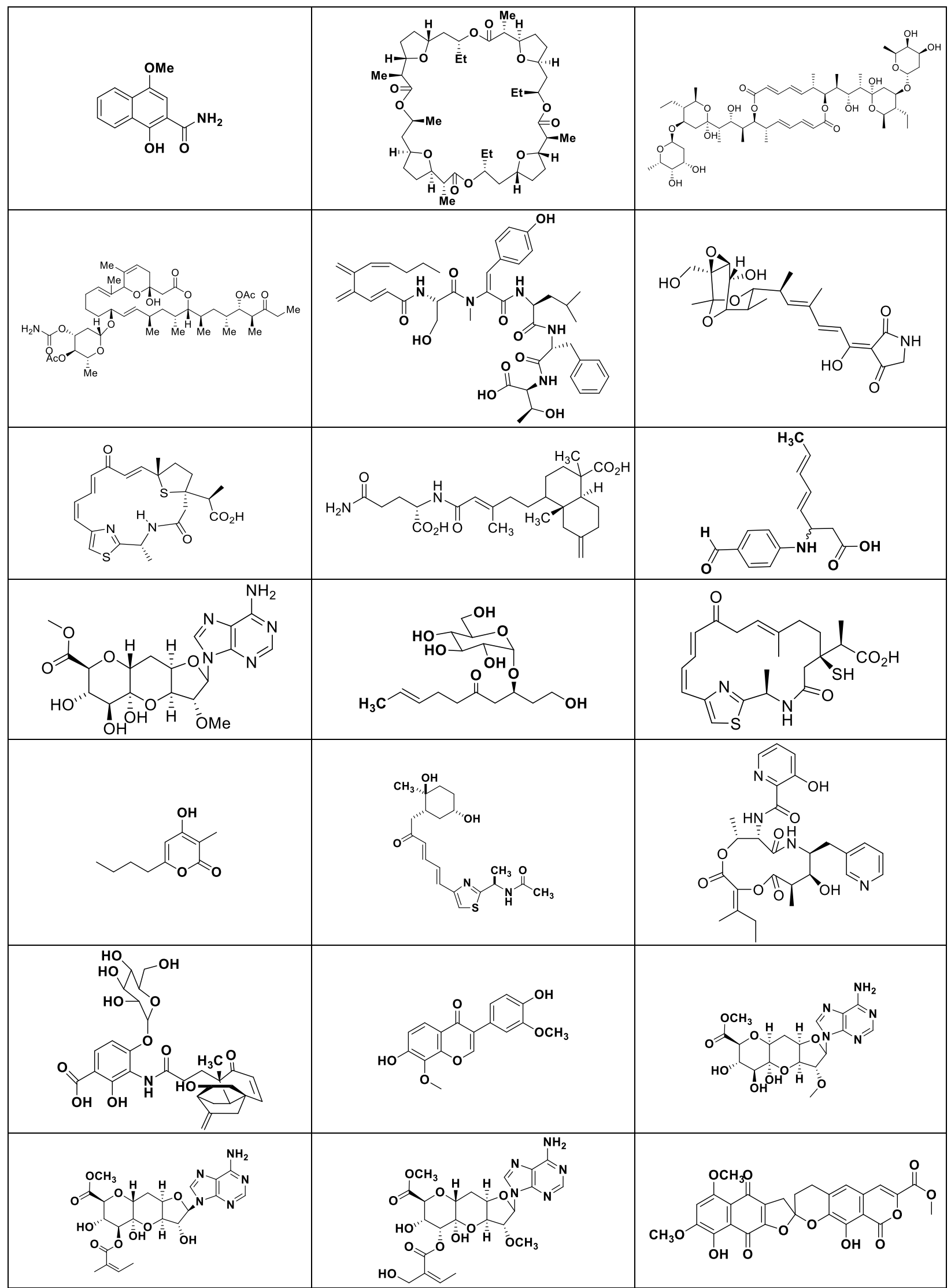




(n)

Figure S1. Structures of the selected 72 pure NPs used in this study. 

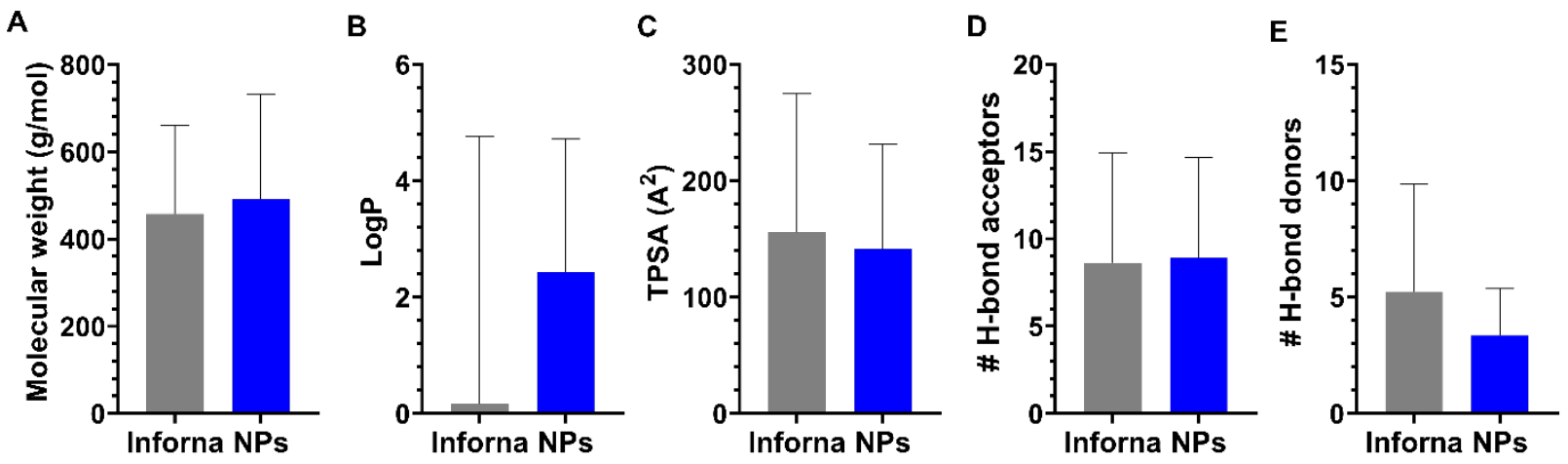

Figure S2. The average physicochemical properties of the 72 NPs (Figure S1) selected for this study as compared to known RNA binders housed in the Inforna database. A) Molecular weight, B) LogP, C) Total polar surface area (TPSA), D) Number of hydrogen bond acceptors, and E) Number of hydrogen bond donors. 
A

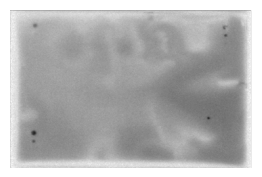

B

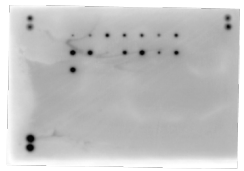

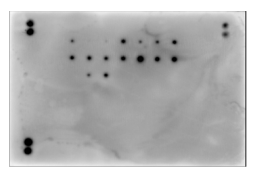

C

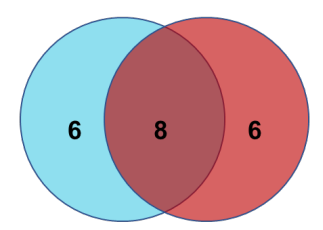

Hits number for $3 \times 3$ ILL Hits number for $3 \times 2$ ILL

Overlapped hits number

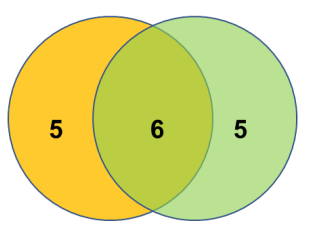

Hit extracts number for $3 \times 3$ ILL Hit extracts number for $3 \times 2$ ILL

Overlapped hit extracts number

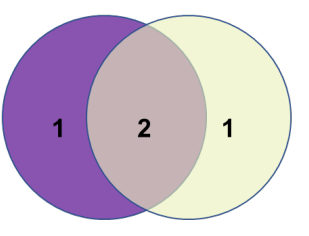

Hit fractions number for $3 \times 3$ ILL Hit fractions number for $3 \times 2$ ILL

Overlapped hit fractions number

Figure S3. Secondary validation of compounds that bind $3 \times 3$ and $3 \times 2$ ILLs from screening the pilot library. A) Representative microarrays for the primary screening of samples that bind RNA structures. B) Representative microarray for the secondary validation of the 14 hits that bind $3 \times 3$ ILL (left) and 14 hits that bind $3 \times 2$ ILL (right) from the primary screen. C) Venn diagrams of the total number of hits from the pilot study for $3 \times 3$ and $3 \times 2$ ILLs (left), number of hit extracts for both ILLs (middle), and the number of hit partially purified fractions for both ILLs (right). Note, the Venn diagrams do not include the 72 pure NPs that were screened. Of these, only one, NOC-I, bound (and bound both ILLs). For $\mathbf{A}$ and $\mathbf{B}$, a positive control small molecule (mitoxantrone) was spotted at the top left, bottom left, and top right corners. See Figure S5 for the secondary validation and 2DCS selection for NOC-I. 


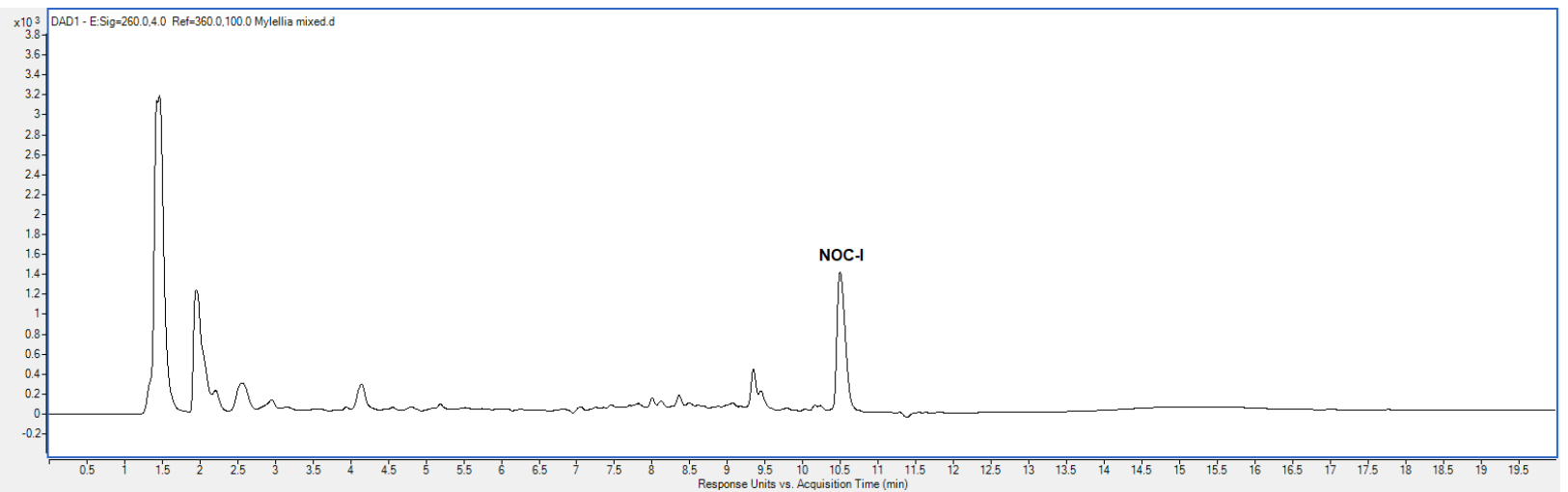

Figure S4. NOC-I was detected in the combined extracts from mycelia and EtOAc extract of fermentation broth (detected at the wavelength of $260 \mathrm{~nm}$ ). 

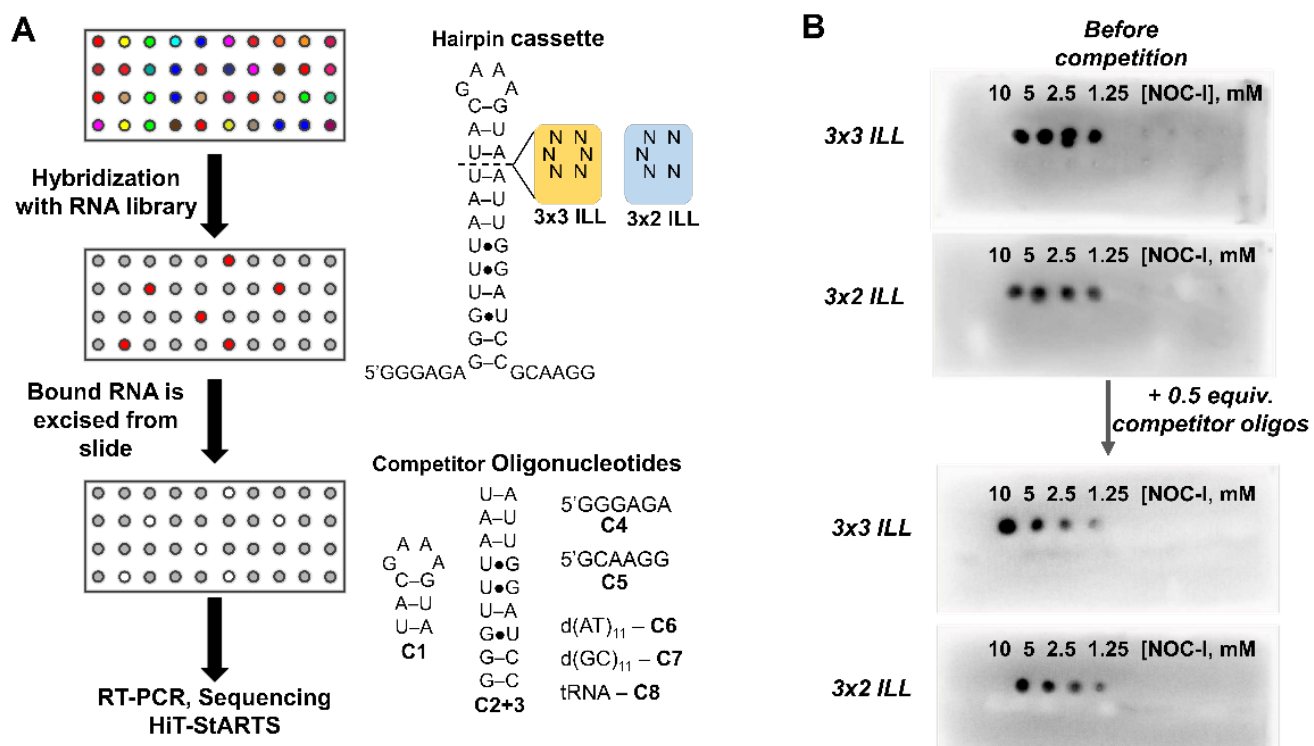

Figure S5. AbsorbArray ${ }^{6}$ and 2DCS selects the RNA 3D folds preferred by NOC-I. A) Schematic of AbsorbArray. The secondary structures of the RNA libraries and competitor oligonucleotides are shown to the right. B) Representative images of NOC-I microarrays after incubation with $3 \times 3$ ILL and $3 \times 2 \mathrm{ILL}$ in the absence or presence of competitor oligonucleotides. 
A

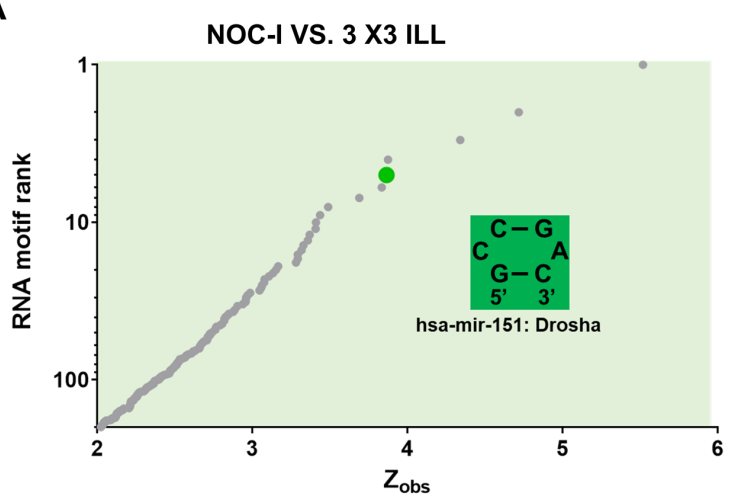

C

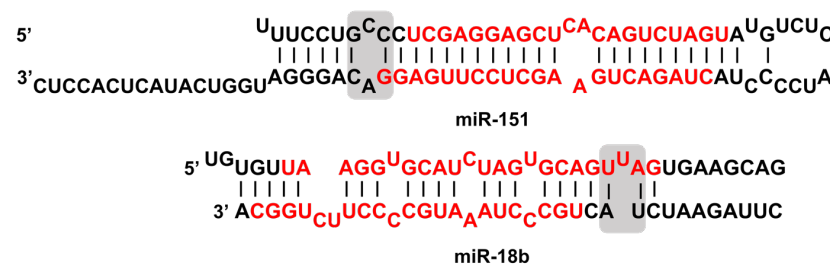

B

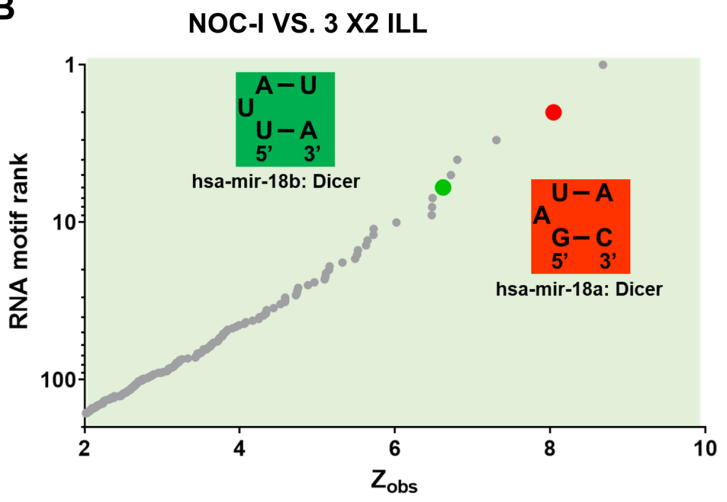

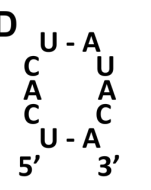

${ }_{5^{\prime}}^{C^{U}} \underset{3^{\prime}}{C^{C}}$

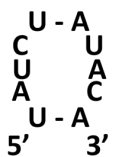

${ }_{5^{\prime}}^{\mathrm{C}^{\mathrm{C}-\mathrm{G}^{\mathrm{C}}}} \underset{3^{\prime}}{\mathrm{C}}$

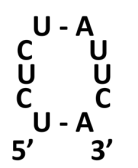

$\underset{5^{\prime}}{U_{U}^{U}-A_{3^{\prime}} C}{ }^{A} C$

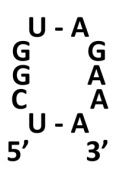

$\underset{5^{\prime}-A_{3^{\prime}}}{C^{C-G}}{ }_{5^{\prime}}^{U-G_{3^{\prime}}}$

Figure S6. RNA 3D folds preferred by NOC-I, identified by the 2DCS selection and statistical analysis of RNA-seq data. A) RNA 3D folds from the $3 \times 3$ ILL preferred by NOC-I, including a structure found in miR-151's Drosha processing site. B) RNA 3D folds from the $3 \times 2$ ILL preferred by NOC-I, including structures found miR-18b's and miR-18a's Dicer processing sites. C) Secondary structures of miR-151 and miR-18b hairpin precursors. D) New RNA folds added to Inforna database which previously did not have binders. 

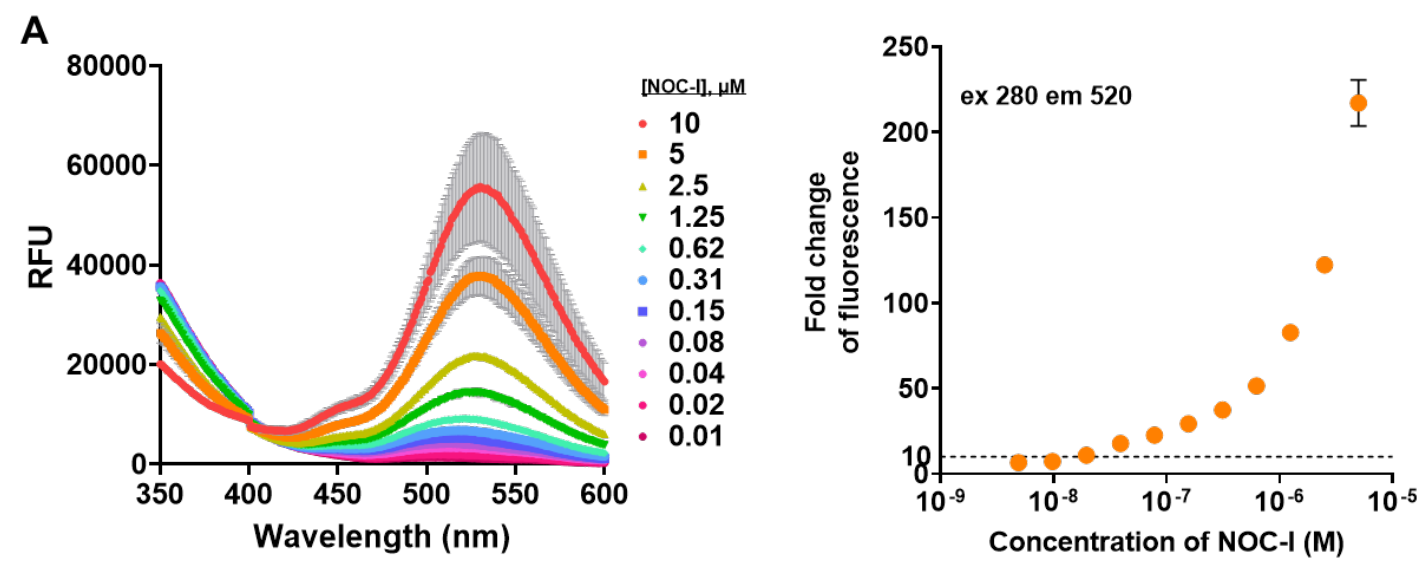

B

C
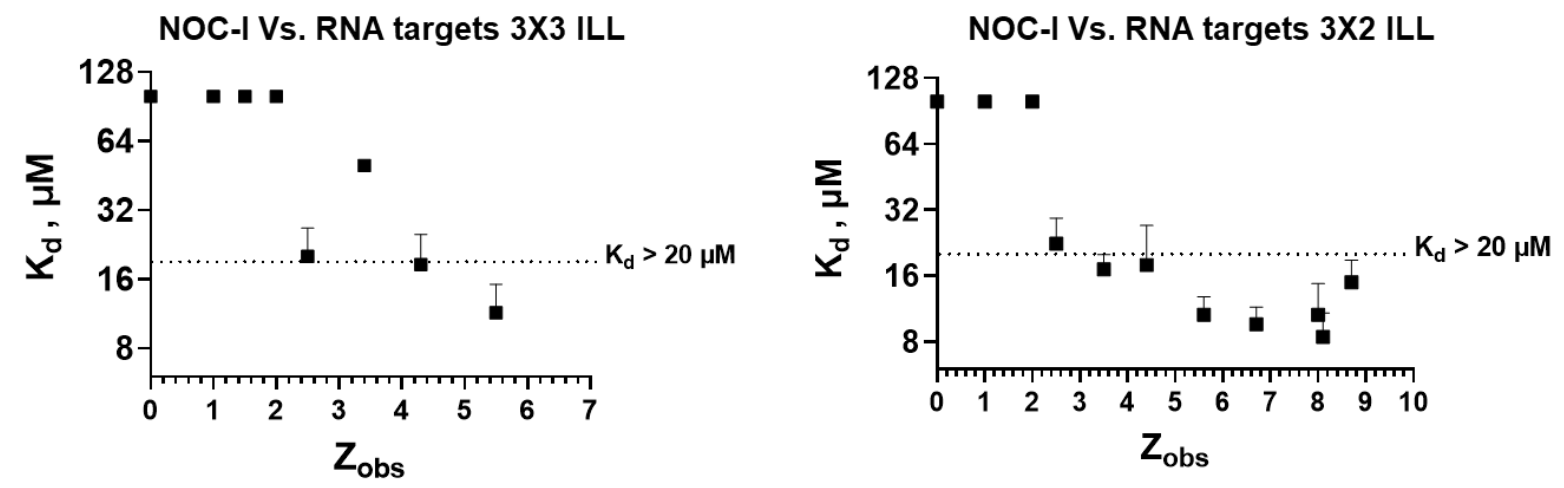

D

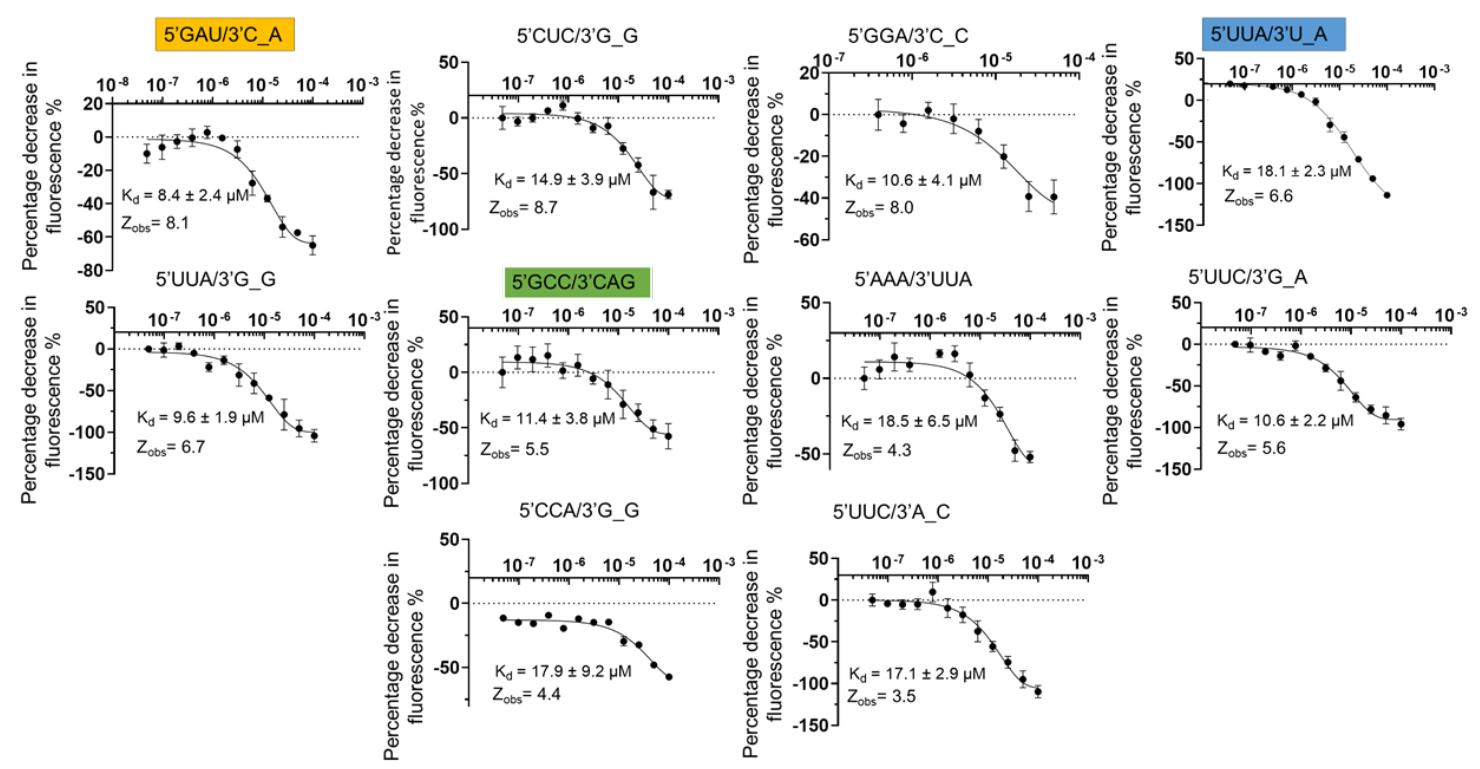

Figure S7. Fluorescence of NOC-I and binding affinities of the RNA folds preferred by NOC-I correlate with $Z_{\text {obs }}$, that is the statistical significance of their enrichment in the 2DCS selection. A) NOC-I has maximum emission at $520 \mathrm{~nm}$ when excited by $280 \mathrm{~nm}$ light (left) and fluorescence 
intensity increases as a function of NOC-I concentration (right). A concentration of $50 \mathrm{nM} \mathrm{NOC-I}$ was chosen for binding assays as it affords a 10 -fold increase in signal above background. B) $K_{d}$ values as a function of statistical significance of enrichment $\left(Z_{\text {obs }}\right)$ for 8 RNA 3D folds derived from the $3 \times 3$ ILL. C) $K_{d}$ values as a function of statistical significance of enrichment $\left(Z_{\text {obs }}\right)$ for 11 RNA $3 \mathrm{D}$ folds derived from the $3 \times 2$ ILL. D) Representative binding curves for RNA 3D folds and NOCI used to generate the curves in panels B and C. Direct, in-solution fluorescence binding measurements (Ex: $280 \mathrm{~nm}$, Em: $520 \mathrm{~nm}$ ) were conducted by measuring the change in the inherent fluorescence of NOC-I as a function of RNA concentration. The RNA motif in yellow box is present in miR-18a, the one in blue box is present in miR-18b and the one in green box is present in miR-151. 

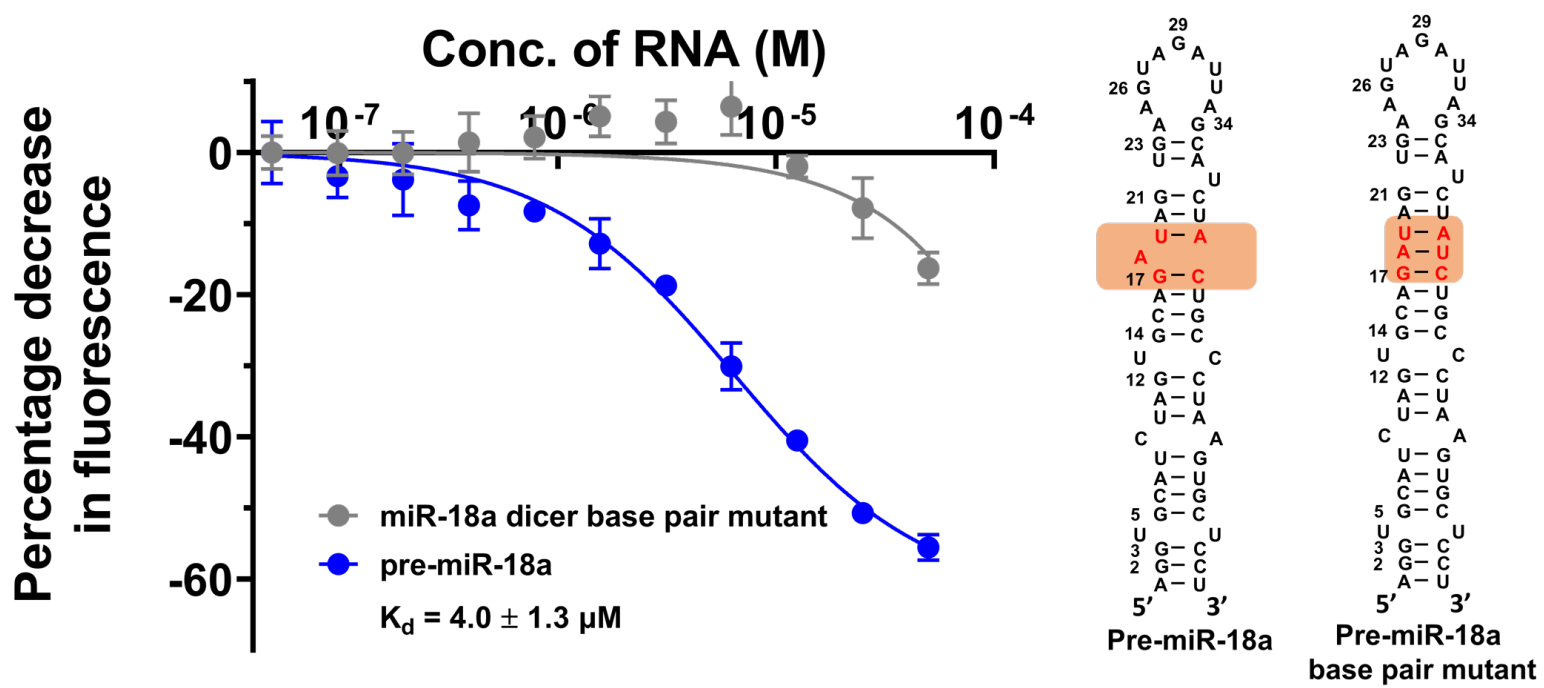

Figure S8. NOC-I binds pre-miR-18a's Dicer site avidly. A) Representative binding curves for the binding affinity measured by a direct, in-solution fluorescence binding assay. B) Secondary structure of wild type pre-miR-18a Dicer site (left) and its mutant in which the A bulge, NOC-I's binding site, is converted to an AU pair. 
A

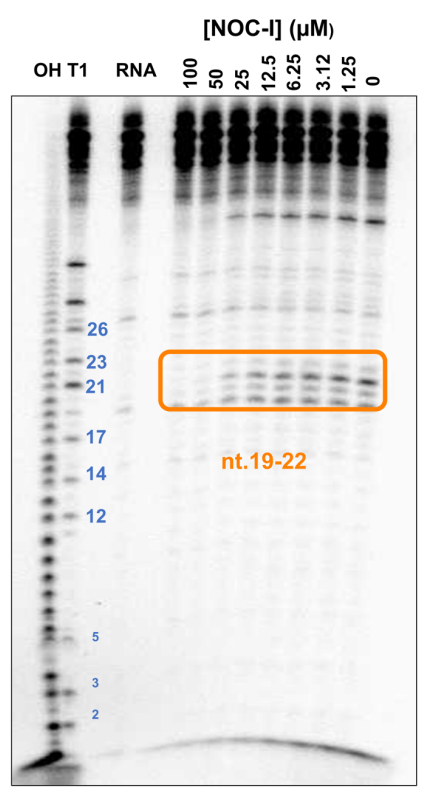

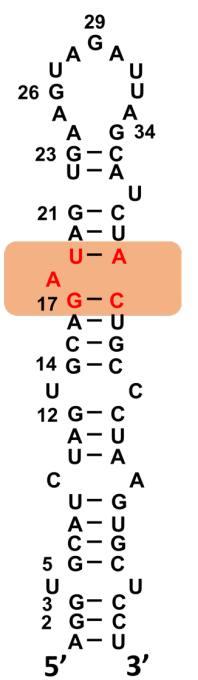

Pre-miR-18a
B

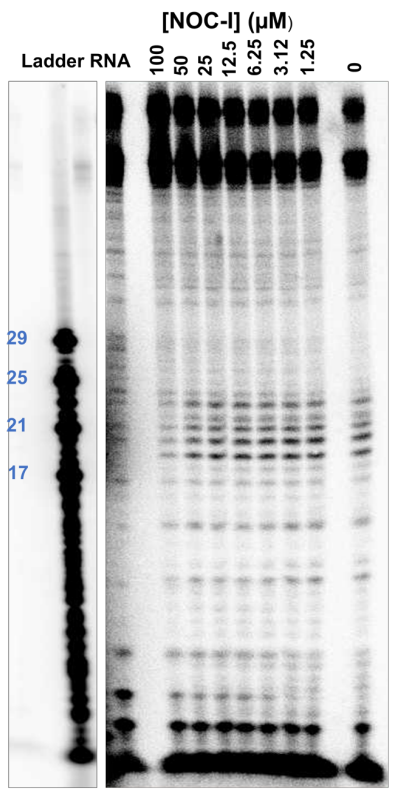

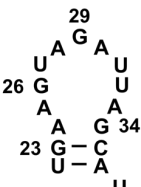

$$
\begin{aligned}
& 21 \mathrm{G}-\mathrm{C}^{\circ} \\
& \begin{array}{l}
A-U \\
U-A \\
A-U
\end{array} \\
& \begin{array}{l}
A-U \\
G-C
\end{array} \\
& \text { A-U } \\
& 14 \stackrel{C}{G}-\mathrm{C} \\
& 14 \mathrm{G} \\
& 12 \mathrm{G}-\mathrm{C} \\
& \text { A-U } \\
& c{ }_{U-G}{ }^{A} \\
& \begin{array}{r}
A-C \\
C-G
\end{array} \\
& { }_{3} \mathrm{G}-\mathrm{C}^{\mathrm{U}} \\
& \begin{array}{cc}
3 & G-C \\
2 & G-C \\
5^{\prime} &
\end{array}
\end{aligned}
$$

Pre-miR-18a base pair mutant

C

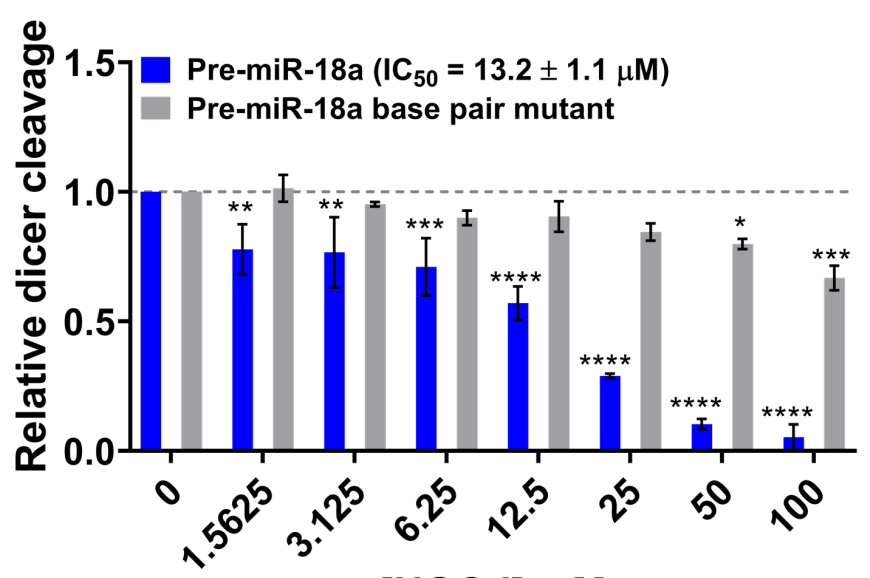

[NOC-I], $\mu \mathrm{M}$

Figure S9. NOC-I inhibits processing of pre-miR-18a by Dicer in vitro. A) Representative gel autoradiogram showing the dose dependent inhibition of the Dicer processing of pre-miR-18a by NOC-I. B) Representative gel autoradiogram showing that NOC-I is unable to inhibit the Dicer processing of a mutant pre-miR-18a where the NP's binding site has been abolished. C) Quantification of gel autoradiograms of Dicer cleavage relative to untreated samples as a function of NOC-I concentration for both wild type and mutant pre-miR-18a. All p-values are calculated using one-way ANOVA where, ${ }^{*}, p<0.05 ;{ }^{* *}, p<0.01 ;{ }^{* *}, p<0.001 ;{ }^{* * * *}, p<0.0001$. Data are reported as the mean \pm S.E.M.. 


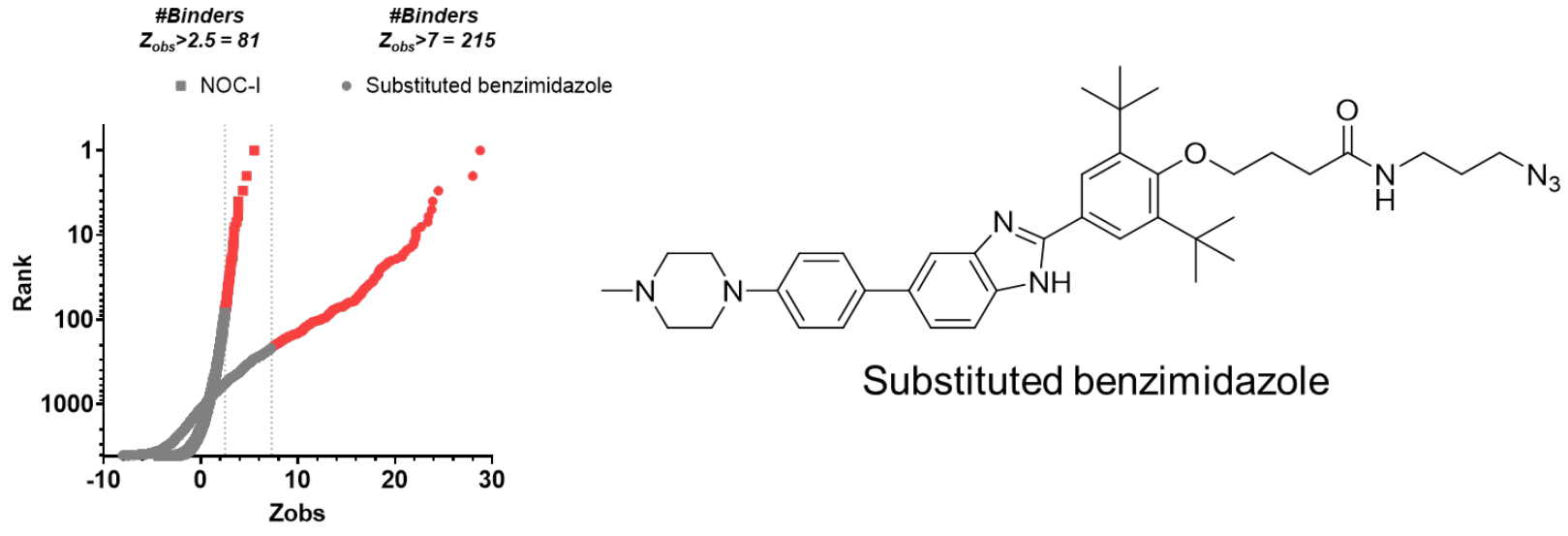

Figure S10. The selectivity of NOC-I and the previously identified substituted benzimidazole that inhibits miR-18a biogenesis for RNA 3D folds, as predicted by HiT-StARTS analysis. The number of RNA motifs that NOC-I and a previously identified substituted benzimidazole ${ }^{7}$ (see also Table S3) are predicted to bind was calculated for their corresponding $Z_{\text {obs }}$ cut-offs of 2.5 and 7 , respectively. 


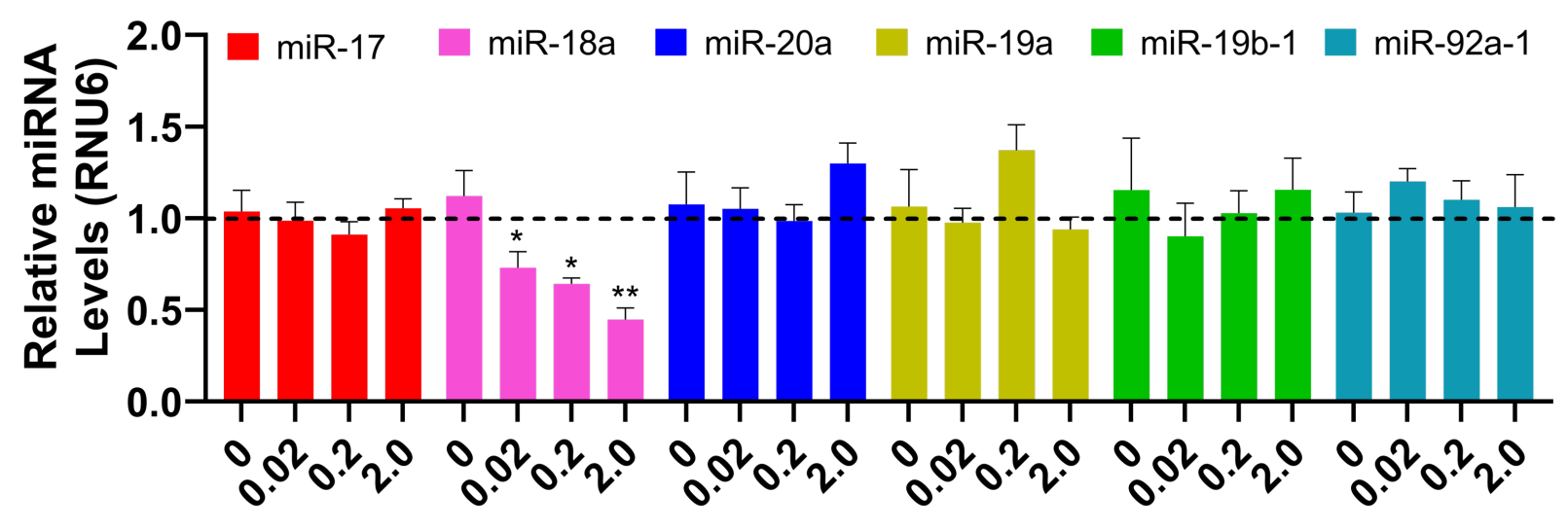

[NOC-I], $\mu \mathrm{M}$

Figure S11. Effect of NOC-I on mature miRNA levels of miR-17/92 cluster members as measured by RT-qPCR. 


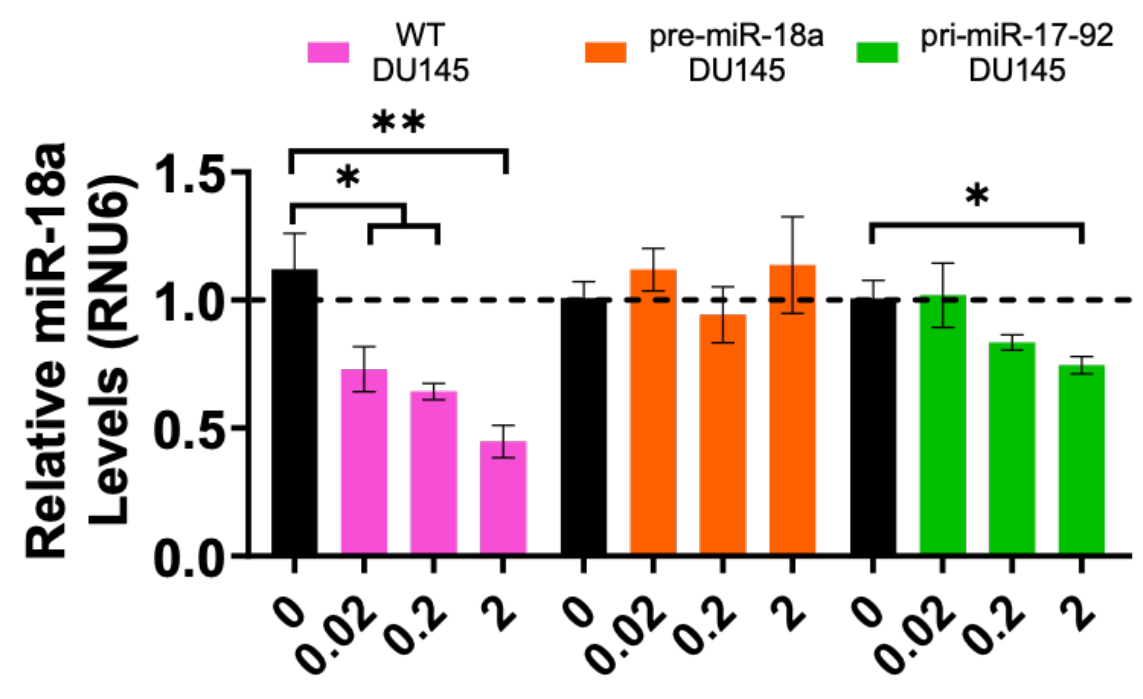

[Nocathiacin-1], $\mu \mathrm{M}$

Figure S12. Forced expression of pre-miR-18a or pri-miR-17/92 reduces the activity NOC-I in DU-145 prostate cancer cells, as assessed by measurement of mature miR-18a levels by RTqPCR. RT-qPCR analysis of untreated cells showed that forced expression increased pre-miR18a levels by $\sim 3$-fold and pri-miR-17/92 levels by $\sim 2$-fold, as compared to endogenous levels in DU-145 cells. 
A

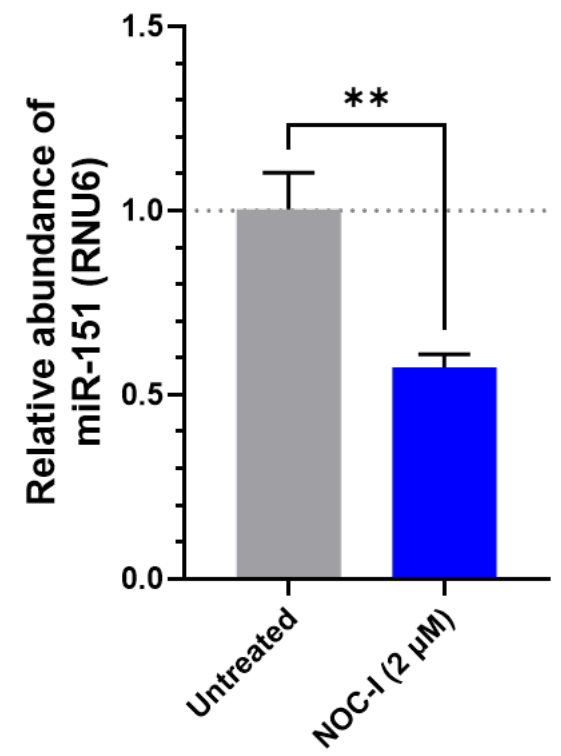

B

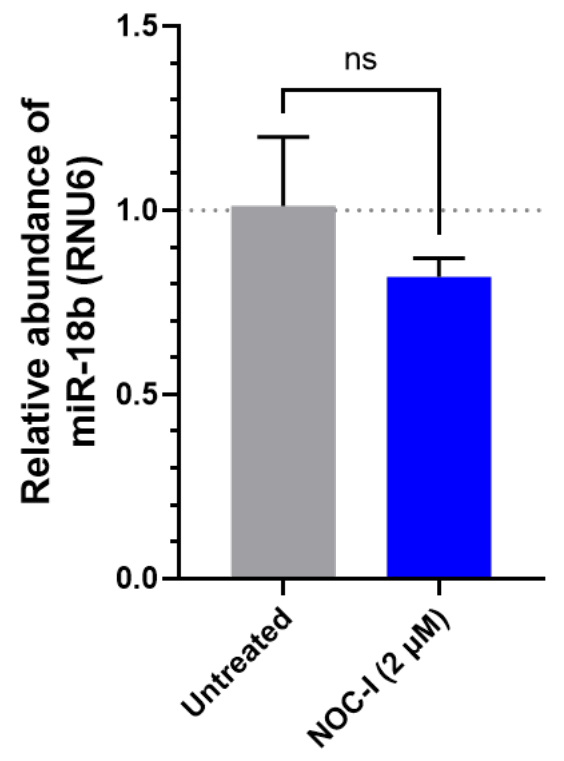

Figure S13. The effect of NOC-I on other miRNA targets predicted by Inforna. A) Relative abundance of miR-151 as measured by RT-qPCR upon treatment of DU-145 cells with $2 \mu \mathrm{M}$ of NOC-I for $48 \mathrm{~h}$. Error bars indicate SD $(n=3)$. B) Relative abundance of miR-18b as measured by RT-qPCR upon treatment of DU-145 cells with $2 \mu \mathrm{M}$ of NOC-I for $48 \mathrm{~h}$. Error bars indicate SD $(n=3)$. 


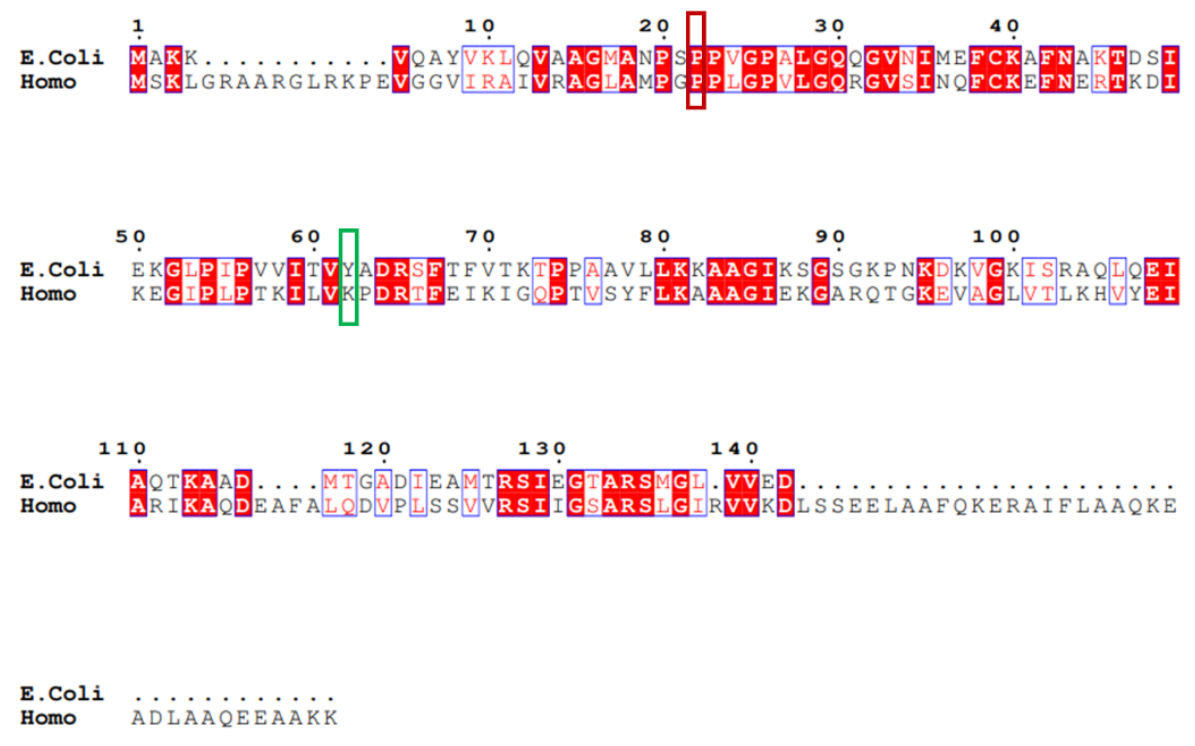

Figure S14. Sequence alignment of Escherichia coli and human ribosomal protein L11. Prolines highlighted with red boxes are critically dependent for the binding of thiostrepton and hence its inhibitory activity (putative mechanism). ${ }^{13,14}$ The amino acid in green box indicates the junction of the $\mathrm{N}$ and $\mathrm{C}$-terminal domains of protein L11 when complexed to rRNA. ${ }^{13,14}$ 


\section{REFERENCES}

1. Velagapudi, S. P., Gallo, S. M., and Disney, M. D. (2014) Sequence-based design of bioactive small molecules that target precursor microRNAs, Nat. Chem. Biol. 10, 291-297.

2. Steele, A. D., Teijaro, C. N., Yang, D., and Shen, B. (2019) Leveraging a large microbial strain collection for natural product discovery, J. Biol. Chem. 294, 16567-16576.

3. Bérdy, J. (2012) Thoughts and facts about antibiotics: Where we are now and where we are heading, J. Antibiot. 65, 385-395.

4. 20.4.0, I. J., ChemAxon (https://www.chemaxon.com).

5. Adhikari, A., Teijaro, C. N., Yan, X., Chang, C.-Y., Gui, C., Liu, Y.-C., Crnovcic, I., Yang, D., Annaval, T., Rader, C., and Shen, B. (2020) Characterization of TnmH as an O-methyltransferase revealing insights into tiancimycin biosynthesis and enabling a biocatalytic strategy to prepare antibodytiancimycin conjugates, J. Med. Chem. 63, 8432-8441.

6. Velagapudi, S. P., Costales, M. G., Vummidi, B. R., Nakai, Y., Angelbello, A. J., Tran, T., Haniff, H. S., Matsumoto, Y., Wang, Z. F., Chatterjee, A. K., Childs-Disney, J. L., and Disney, M. D. (2018) Approved anti-cancer drugs target oncogenic non-coding RNAs, Cell Chem. Biol. 25, 1086-1094 e1087.

7. Velagapudi, S. P., Luo, Y., Tran, T., Haniff, H. S., Nakai, Y., Fallahi, M., Martinez, G. J., Childs-Disney, J. L., and Disney, M. D. (2017) Defining RNA-small molecule affinity landscapes enables design of a small molecule inhibitor of an oncogenic noncoding RNA, ACS Cent. Sci. 3, 205-216.

8. Liu, X., Haniff, H. S., Childs-Disney, J. L., Shuster, A., Aikawa, H., Adibekian, A., and Disney, M. D. (2020) Targeted degradation of the oncogenic microRNA 17-92 cluster by structure-targeting ligands, $J$. Am. Chem. Soc. 142, 6970-6982 